\title{
Baseline Water Chemistry Characterization in an Area of Developing Shale Gas Activity
}

Patrick C. Eisenhauer

West Virginia University

Follow this and additional works at: https://researchrepository.wvu.edu/etd

\section{Recommended Citation}

Eisenhauer, Patrick C., "Baseline Water Chemistry Characterization in an Area of Developing Shale Gas Activity" (2013). Graduate Theses, Dissertations, and Problem Reports. 4963.

https://researchrepository.wvu.edu/etd/4963

This Thesis is protected by copyright and/or related rights. It has been brought to you by the The Research Repository @ WVU with permission from the rights-holder(s). You are free to use this Thesis in any way that is permitted by the copyright and related rights legislation that applies to your use. For other uses you must obtain permission from the rights-holder(s) directly, unless additional rights are indicated by a Creative Commons license in the record and/ or on the work itself. This Thesis has been accepted for inclusion in WVU Graduate Theses, Dissertations, and Problem Reports collection by an authorized administrator of The Research Repository @ WVU. For more information, please contact researchrepository@mail.wvu.edu. 


\title{
Baseline Water Chemistry Characterization in an Area of Developing Shale Gas Activity
}

\author{
Patrick C. Eisenhauer \\ Thesis submitted to the \\ Davis College of Agriculture, Natural Resources and Design \\ at West Virginia University \\ in partial fulfillment of the requirements \\ for the degree of \\ Master of Science \\ in \\ Forestry
}

Nicolas Zegre, Ph.D., Chair

Pamela Edwards, Ph.D.

Shikha Sharma, Ph.D.

Michael Strager, Ph.D.

Division of Forestry and Natural Resources

Morgantown, West Virginia

2013

Keywords: Groundwater; West Virginia; Unconventional Gas Development; Isotopes Copyright 2013 Patrick C. Eisenhauer 


\title{
ABSTRACT \\ Baseline Water Chemistry Characterization in an Area of Developing Shale Gas Activity
}

\author{
Patrick C. Eisenhauer
}

The recent increase in the development of shale formations for the purpose of natural gas extraction in the mid-Atlantic, namely the Marcellus shale, can be attributed to advances in unconventional extraction methods. This includes horizontal drilling and multistage hydraulic fracturing, a process that uses water to pressurize and fracture relatively impermeable shale layers to release natural gas. In West Virginia, the U.S. Department of Energy estimates 95 to 105 trillion cubic feet (TCF) of expected ultimate recovery (EUR) of natural gas from this formation [ALL Consulting, 2010]. Increased development of unconventional shale gas formations are accompanied by concerns of potential contamination to shallow groundwater resources, which often serve as potable water sources for many rural communities. However, the impacts of this practice on water resources are poorly understood due to lack of controlled preversus post-drilling monitoring, a consequence attributed to the rapid development of this resource.

To address knowledge gaps associated with the potential impacts of unconventional shale gas development on water resources, a pre-versus post-drilling study has been initiated by the USFS in the Monongahela National Forest. This study consists of three major objectives; (1) a comprehensive literature review examining the current state of understanding about unconventional natural gas extraction and its potential to impact shallow groundwater resources; (2) the development of a sampling protocol that outlines equipment and procedures necessary for the collection of water samples for the purpose of this study; (3) the characterization of surface and groundwater chemistry used for direct and indirect sources of drinking water in the Summit Lake area of the Monongahela National Forest prior to drilling, establishing baseline water chemistry conditions. Pre-drilling water samples were collected and analyzed from two groundwater wells, a shallow spring, a nearby lake, and a river to identify potential endmembers. Geochemical analyses included major ions, trace elements, dissolved methane concentrations, carbon and hydrogen isotope concentrations of dissolved methane $\left(\delta^{13} \mathrm{C}_{\mathrm{CH} 4}\right.$ and $\left.\delta^{2} \mathrm{H}_{\mathrm{CH} 4}\right)$, oxygen and hydrogen isotope compositions in water $\left(\delta^{2} \mathrm{H}_{\mathrm{H} 20}\right.$ and $\left.\delta^{18} \mathrm{H}_{\mathrm{H} 20}\right)$, sulfur and oxygen isotope compositions of dissolved sulfate $\left(\delta^{34} \mathrm{~S}_{\mathrm{SO} 4}\right.$ and $\left.\delta^{18} \mathrm{O}_{\mathrm{SO} 4}\right)$, carbon compositions of dissolved organic carbon $\left(\delta^{13} \mathrm{C}_{\text {DIC }}\right)$, and radium isotopes $\left({ }^{226} \mathrm{Ra}\right.$ and $\left.{ }^{228} \mathrm{Ra}\right)$. This analysis serves as a baseline of local water chemistry around Summit Lake, West Virginia, from which to evaluate potential changes before, during, and after shale gas extraction. 


\section{ACKNOWLEDGMENTS}

I would like to sincerely thank my friend and thesis advisor, Dr. Nicolas Zegre, whose passion and excitement for hydrology inspired my academic endeavors. His belief in me and commitment to the process provided the motivation and confidence to persist. His guidance was imperative to my success as he went above and beyond his role as my advisor.

Additionally, I would like to acknowledge the members of my thesis committee, Pamela Edwards, Shikha Sharma, and Michael Strager, whose diverse backgrounds provided valuable insights along the way. Funding sources included the USFS Northern Research Station and the WVU Division of Forestry and Natural Resources. Without their support this project would not have been possible, and I am thankful for their commitment to the type of education that will shape the professionals of my generation and many generations to follow.

I would also like to thank Andrew Miller for his assistance in and out of the field. Many hours of stressful work together evolved into strong friendship which allowed me to maintain my sanity throughout this experience. I would also like to thank Jeremy White of the USGS West Virginia Water Science Center. The cooperation and resources of the USGS in field sampling were an essential component of this project.

Lastly completing this work would not have been possible without relentless encouragement and support from my family and friends.

Patrick C. Eisenhauer

West Virginia University

May, 2013 


\section{TABLE OF CONTENTS}

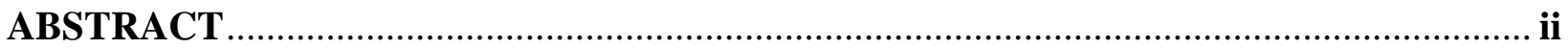

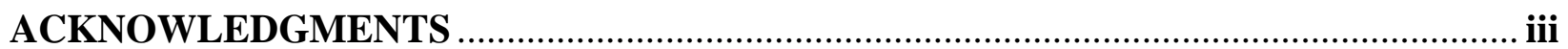

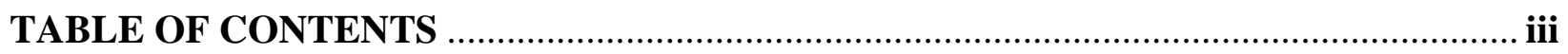

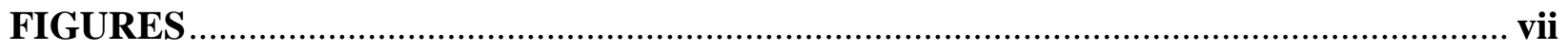

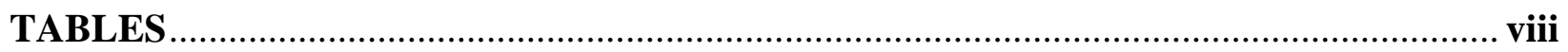

Section 1.0 - Introduction and Objectives ...................................................................

1.1 - Unconventional shale gas development ............................................................................1

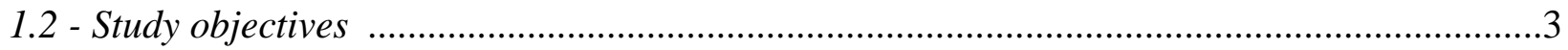

Section 2.0 - Water Quality Impacts from Unconventional Natural Gas Extraction in the

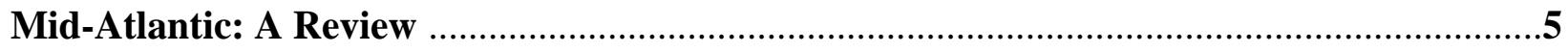

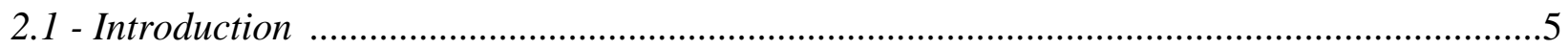

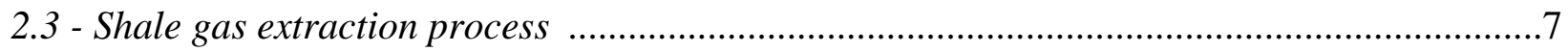

2.3.1 - Conventional vs. Unconventional gas extraction ..............................................

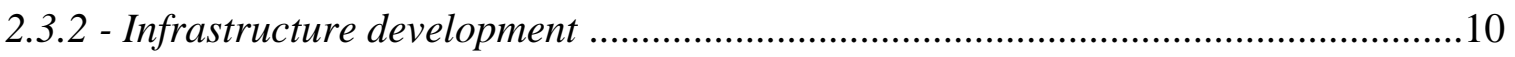

2.3 .3 - Drilling and casing process ................................................................... 11

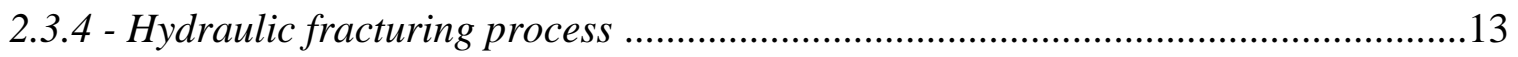

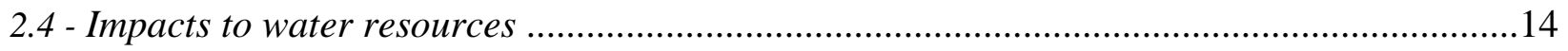

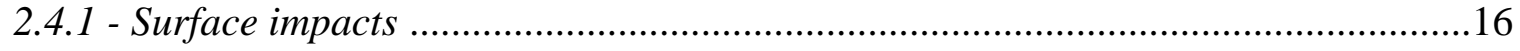

2.4.1a - Water withdrawal impacts ............................................................17

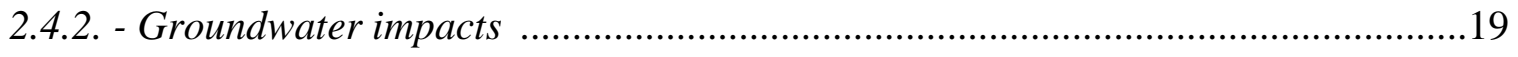

2.4.2a - Surface driven groundwater impacts...............................................19

2.4.2b - Subsurface driven groundwater impacts ...........................................20

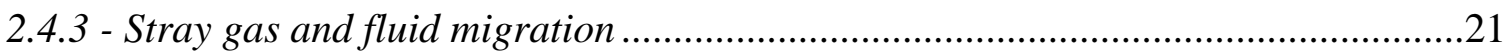

2.4.3a - Transport pathways for gas and fluid migration from depth ..................24 


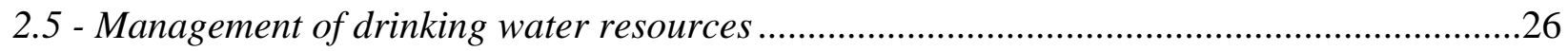

2.5.1 - Conceptual model development ..................................................................26

2.5.2 - Knowledge gaps, research techniques, and management ..................................27

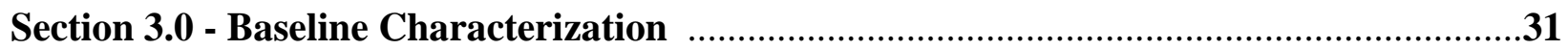

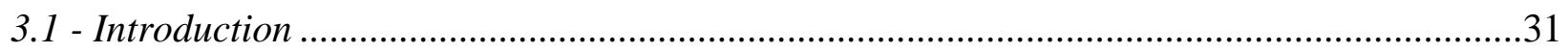

3.2 - Application of major ions, isotope geochemistry and trace metals to groundwater

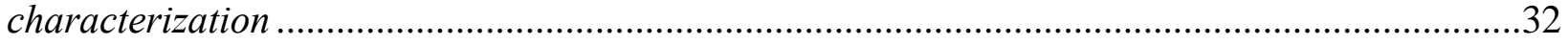

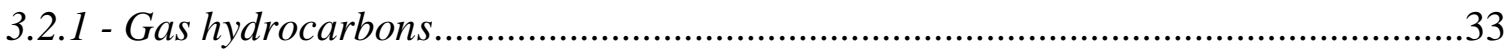

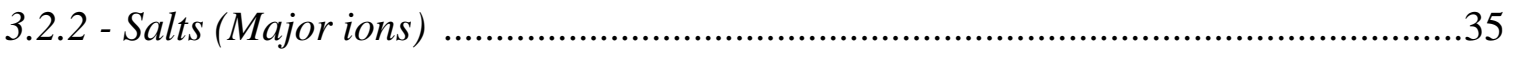

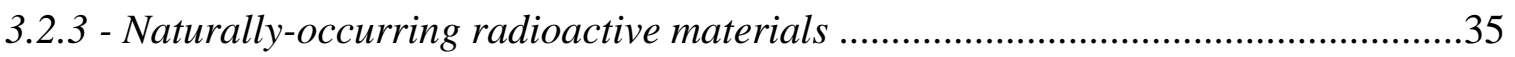

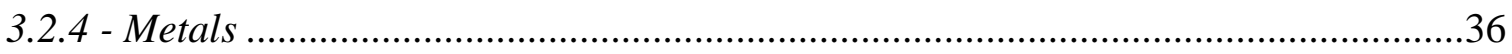

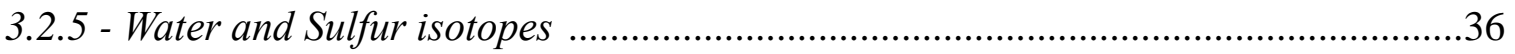

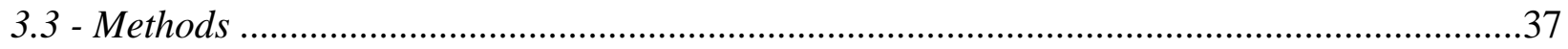

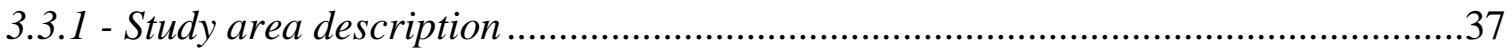

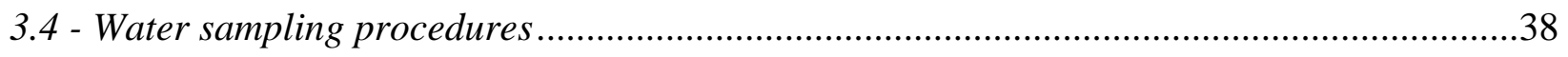

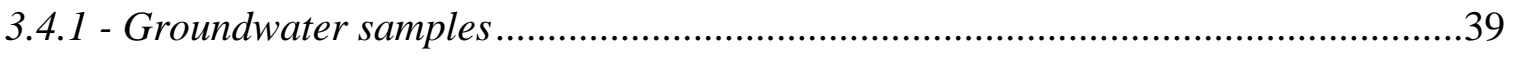

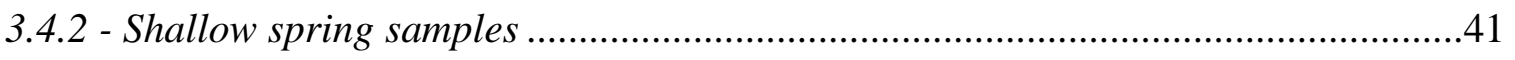

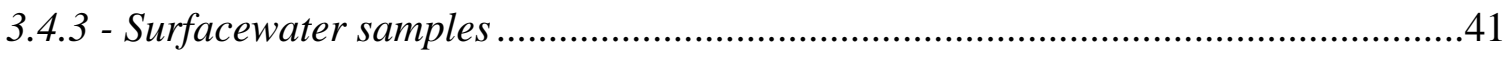

3.5 - Baseline characterization of water chemistry ..............................................................42

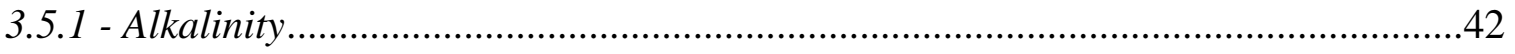

3.5.2 - Major ions and trace metals analysis ............................................................43

3.5.3 - Isotopic analysis for methane, water, sulfur, and radium ...................................44

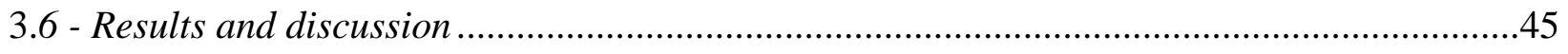

3.6.1 - Methane concentrations and signatures in groundwater ..................................45

3.6.2 - Isotopic signatures of sampling locations ......................................................46 


\section{FIGURES}

Figure 1: Primary energy use of the United States by fuel 1980-2035 [US EIA, 2012] 53

Figure 2: Total U.S. Natural Gas Consumption, Domestic Production, and Net Imports 19902035 [US EIA, 2012] 53

Figure 3: Map of current U.S. shale gas and shale oil plays [US EIA, 2011] ............................. 54

Figure 4: The Marcellus shale and the Appalachian shale gas basin....................................... 54

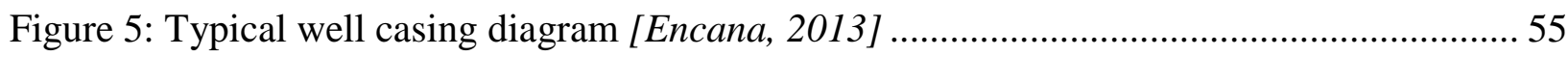

Figure 6: Conceptual model of potential unconventional gas development integrating surface and subsurface impacts on drinking water quality ...... 56

Figure 7: Proposed drilling and current sampling locations in the Cherry River Watershed on the

Monongahela National Forest ............................................................................................... 57

Figure 8: Accessing the Summit Lake well supported by a block and beam system ................... 58

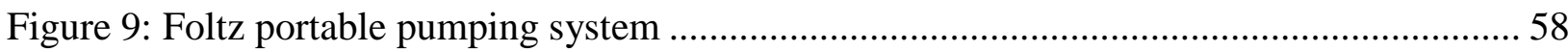

Figure 10: Quick connect coupler and pipe flange for sampling at the spring box ......................59

Figure 11: Geologic cross section of Summit Lake West Virginia [MacDonald, 1965] .............. 60

Figure 12: Geologic map of Summit Lake West Virginia [MacDonald, 1965] ........................... 60

Figure 13: Longstanding and recently proposed gas operations in Monongahela National Forest 


\section{TABLES}

Table 1: Conventional vs. Unconventional natural gas extraction methods............................. 62

Table 2: Comparison of literature end members for determining sources of methane................ 62

Table 3: EPA Maximum Contaminant Levels (MCL) for radioactive elements / particles in

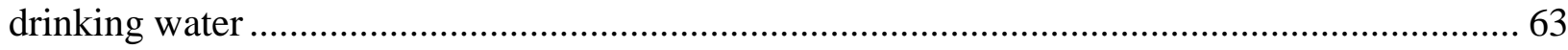

Table 4: Field parameters of sampling locations near Summit Lake West Virginia ................... 63

Table 5: EPA Maximum Contaminant Levels (MCL) \& Secondary Standards for salts and pH in groundwater

Table 6: EPA Maximum Contaminant Levels (MCL) \& Secondary Standards for metals in drinking water $\&$ associated health effects

Table 7: ICP-MS analysis, trace metal concentrations of sampling locations in Summit Lake West Virginia.

Table 8: ICP-MS analysis, trace metal concentrations of sampling locations in Summit Lake

West Virginia.

Table 9: ICP-MS analysis, trace metal concentrations of sampling locations in Summit Lake

West Virginia.

Table 10: ICP-MS analysis, trace metal concentrations of sampling locations in Summit Lake West Virginia.

Table 11: ICP-MS analysis, trace metal concentrations and Alkalinity of sampling locations in Summit Lake West Virginia.

Table 12: Isotopic signatures of sampling locations in Summit Lake West Virginia. All units in $\%$ less otherwise noted.

Table 13: Field hydrochemistry of sampling locations (Anions) in Summit Lake West Virginia. 


\section{Section 1.0 - Introduction and Objectives}

\section{1 - Unconventional shale gas development}

Renewed interest in natural gas production as part of the United States energy portfolio has directed significant attention towards unconventional shale formations throughout the United States. Increases in the economic feasibility of unconventional reservoirs including coalbed methane, methane hydrates, and tight shale gas plays are credited to extraction methods, such as horizontal drilling and multi-stage hydraulic fracturing [DOE and NETL, 2009]. In 2010, natural gas accounted for approximately $25 \%$ of the total energy consumed by fuel in the United Sates and projections show increases in the production of domestic shale gas through 2035 (Figure 1 and 2) [US EIA, 2012]. In West Virginia, the Department of Energy estimates 95 to 105 trillion cubic feet (TCF) of expected ultimate recovery (EUR) of natural gas form this formation, which will constitute significant new drilling in the state [ALL Consulting, 2010]. The desire to achieve greater energy independence will unquestionably include the development of unconventional gas reservoirs in the mid-Atlantic, including West Virginia and associated environmental challenges.

Large shale gas reservoirs currently contribute over $23 \%$ of domestic gas production and include the Barnett, Antrim, Fayetteville, New Albany, Haynesville, and Marcellus shales (Figure 3) [US EIA, 2011]. All of these geologic formations have undergone recent development in the mid-Atlantic; however the Marcellus, which has the potential to become the second largest gas producing field in the world, has been described as the most expansive shale gas play, at $24000 \mathrm{~km}^{2}$ in size [Engelder, 2009; Kargbo et al., 2010]. This sedimentary rock formation, deposited over 350 million years ago, spans from southern New York through Pennsylvania and into West Virginia with extensions into Ohio and western Maryland [Soeder and Kappel, 2009]. The organic-rich Marcellus shale is an unconventional gas reservoir with tight, low porosity 
formation properties that typically lie between 1,200 to 2,400 meters below ground [Blauvelt, 2010]. This differs from conventional reservoirs, traditionally accessed through vertical drilling, where gas has migrated into a formation that is bound by an impermeable upper layer. In order to produce an economical volume of gas from unconventional reservoirs in the Appalachian basin, such as the Marcellus shale and more recently explored Utica shale, horizontal drilling has been combined with multi-stage hydraulic fracturing techniques. Horizontal drilling is the preferred method for drilling unconventional shale deposits as it allows for greater formation exposure and, therefore, fracturing which can lead to large gas production potentials [Blauvelt, 2010]. Hydraulic fracturing is the process by which water is used to pressurize and fracture relatively impermeable shale reservoirs to facilitate movement of natural gas. In this process, chemicals are used to facilitate the movement of water down the well casing and into the formation, causing fracturing. A proppant, usually sand, then supports the newly created fractures when the pressures are released. This process constitutes a large industrial activity, requiring large volumes of water (11.4 to 18.9 million liters per well) to develop even a single horizontal gas well within the Marcellus [Arthur et al., 2010; DOE and NETL, 2009]. Contamination events that can occur during these operations, such as accidental releases of drilling and hydraulic fracturing fluids, make predicting impacts difficult.

This shift from conventional to unconventional gas extraction through the widespread use of horizontal drilling and multistage hydraulic fracturing has also constituted a shift in environmental implications, particularly related to water resources. These impacts include concerns related to contamination of shallow drinking water aquifers, which supply $42 \%$ of West Virginia residents clean drinking water, water withdrawals used for drilling and production operations, and wastewater handling and the accidental events that can occur [Chambers et al., 
2012; Rahm and Riha, 2012]. Entrekin et al. [2011] noted that quantifying the impacts of natural gas development on water resources remains inherently difficult due to the uncertainty behind location and timing of future drilling operations. Difficulty in quantifying impacts is compounded by various levels of compliance required across state and local agencies, as well as differentiating impacts to watersheds from previous anthropogenic activity. As such, extensive baseline water sampling remains essential and should be conducted routinely throughout gas development areas before, during, and after the shale gas development process.

\section{2 - Study objectives}

In order to evaluate potential impacts to water resources via unconventional shale gas development, this review focuses on three major objectives; (1) a comprehensive literature review examining the current state of understanding about unconventional natural gas extraction and its potential to impact shallow groundwater resources: (2) the development of a sampling protocol that outlines equipment and procedures necessary for the collection of water samples for the purpose of this study; (3) the characterization of surface and groundwater chemistry used for direct and indirect sources of drinking water in the Summit Lake area of the Monongahela National Forest prior to drilling, establishing baseline water chemistry conditions. An original objective of this study included the development of a groundwater flow model but, due to the paucity of data this objective was determined to be unfeasible for this study location. Important benefits of collecting hydrogeologic data in this area do exist and are outlined, in addition to suggestions for future studies.

In order to accomplish the objectives of this study it was necessary to:

1. Gather and synthesize peer reviewed research, conducted throughout the United States, related to the impacts of unconventional natural gas development on surface and 
groundwater quality in order to establish a comprehensive understanding of potential impacts and current stresses on drinking water reservoirs.

2. Develop a protocol that provides a framework for (1) incorporating guidelines for accessing sampling locations; (2) discussing the equipment necessary for sampling at each location; and (3) systematizing the procedures used for sampling and analysis.

3. Collect and report surface and groundwater conditions (5 locations) through a hydrochemical (major ions) and isotopic analysis $\left(\delta^{13} \mathrm{C}_{\mathrm{CH} 4}, \delta^{2} \mathrm{H}_{\mathrm{CH} 4}, \delta^{13} \mathrm{C}_{\mathrm{DIC}}, \delta^{2} \mathrm{H}_{\mathrm{H} 20}, \delta^{18} \mathrm{O}_{\mathrm{H} 20}\right.$, $\delta^{34} \mathrm{~S}_{\mathrm{SO} 4}, \delta^{18} \mathrm{O}_{\mathrm{SO} 4},{ }^{226} \mathrm{Ra}$, and ${ }^{228} \mathrm{Ra}$ ), as a baseline for a pre-versus post-drilling comparison. Laboratories used for analysis included Geo Labs in Ontario, Canada; Test America in Pittsburgh, Pennsylvania; West Virginia University Stable Isotope Laboratory; and Isotech Laboratories Inc., Champaign, IL.

The arrangement of this thesis includes two major sections (Section 2 and 3) that address the aforementioned study objectives followed by a discussion of the overall results including general relevance, limitations, and directions for future research (Section 4). 


\section{Section 2.0 - Water Quality Impacts from Unconventional Natural Gas Extraction in the Mid-Atlantic: A Review}

\section{1 - Introduction}

Recent advances in unconventional natural gas extraction methods, namely horizontal drilling and multi-stage hydraulic fracturing, have drawn attention to shale gas formations throughout the United States. In 2010, natural gas accounted for approximately 25\% of the United States energy portfolio, second only to petroleum (Figure 1), and projections show increases in the production of domestic shale gas through 2035 (Figure 2) [US EIA, 2012]. Large shale gas reservoirs currently contribute over $23 \%$ of domestic production and include Barnett, Antrim, Fayetteville, Haynesville and Marcellus shales (Figure 3). All of these geologic formations have seen recent development; however the Marcellus Shale represents the most expansive reservoir at 24,000 $\mathrm{km}^{2}$ in size [Engelder, 2009; Kargbo et al., 2010]. A rich history of conventional natural gas development exists in the Appalachian region, stemming from its beginnings in Fredonia, New York in 1821 [DOE and NETL, 2009; NYDEC, 2011]. Historically, conventional gas reservoirs were developed using vertical wells drilled from a single pad location. However, increased interest in unconventional gas development, often targeting less porous shale formations, constitutes a change in the scale of gas extraction operations.

The nexus between water and energy is well established. Energy development continues to be heavily dependent on freshwater, and as demand for freshwater increases so does the consumption of energy required to provide it [Sarni and Stanislaw, 2012]. Recently, impacts of unconventional gas development on water resources have been discussed from surface or subsurface perspective, but not both [Entrekin et al., 2011; Osborn et al., 2011]. This one-sided approach frequently leads to a dialogue that is disconnected from cumulative impacts to 
watersheds and fails to incorporate a discussion of gas development operations that should guide prescriptions for management of these water resources. Natural gas operations, including drilling, hydraulic fracturing, and associated infrastructure development (e.g. roads and pipelines); can significantly affect hydrology at the site and headwater scale. However, there remains uncertainty surrounding shale gas extraction's direct impacts to shallow potable aquifers. Key concerns relate to contamination of shallow aquifers that supply many rural residents with drinking water, water withdrawals used for drilling and production operations, and wastewater handling, including accidental events, such as spills, that can occur [Rahm and Riha, 2012].

The focus of this review is to evaluate shale gas energy development effects on surface and shallow subsurface water quality. This is accomplished through connecting literature that describes impacts separately to surface and groundwater resources through discussing their interactions and implications. Unconventional gas development technologies are compared and contrasted to historical drilling and completion practices, specifically focusing on the black shale regions of the mid-Atlantic (Marcellus \& Utica) (Figure 4). Peer reviewed literature, and reports by government and state agencies from across the United States that have larger periods of development are referenced. This approach provides a framework to assess the potential hydrologic impacts related to unconventional shale gas development in the mid-Atlantic. Management of natural gas activities varies from state to state, and concerns regarding management should be considered across scales. Although broader issues are considered when possible, the focus of this review is on cumulative local impacts that can significantly affect headwater catchments and ultimately contribute to basin-level impacts downstream. In an effort to address impacts from shale gas extraction that govern the management of water resources my 
specific objectives are to: (1) draw distinctions between conventional and unconventional gas drilling processes, (2) formulate a conceptual understanding of the impacts of unconventional gas extraction practices to both surface and subsurface water resources, and (3) discuss promising research approaches and techniques that would contribute to understanding of waterrelated impacts from development of unconventional shale gas.

\section{3 - Shale gas extraction process}

\subsection{1 - Conventional vs. unconventional natural gas extraction}

Natural gas is generally categorized by its formation properties and includes both conventional and unconventional reservoirs. Conventional gas reservoirs are visualized as pockets of gas that accumulate under an impermeable rock layer over geologic time. Sources of these reservoirs are often unconventional gas reserves, such as shale gas, where gas is trapped in pore spaces of a relatively low porosity matrix. Extraction of gas from these reservoirs is also uniquely different. Conventional reservoirs are often accessed through the use of vertical wells which require less intrusive hydraulic fracturing techniques to facilitate movement of gas for production. Unconventional reservoirs, frequently accessed through the use of horizontal drilling, require hydraulic fracturing techniques that occur in multiple stages. These wells are designed similarly to vertical wells however the horizontal portion increases the exposure to the shale formation increasing its economic feasibility. Table 1 lists important characteristic differences between conventional and unconventional natural gas extraction, most notably the scale of production activities. The scale of unconventional gas development operations, with its associated environmental impacts, fundamentally separates it from its conventional beginnings. This shift has brought concerns related to shallow drinking water resources. 
Surface impacts to the landscape associated with the exploration of unconventional shale gas in the mid-Atlantic occur through the development of necessary infrastructure. Development comes in the form of new access roads, followed by the construction of storm water systems, drilling pads, freshwater impoundments, and compressor stations, all of which increase landscape fragmentation [Bishop, 2011; Drohan et al., 2012]. These impacts are in addition to gathering and transmission pipelines, which are necessary for the transportation of gas and may cover long distances. However, advancements in drilling technology in the form of horizontal drilling ultimately will reduce land disturbance during resource extraction. The initial footprint of a horizontal drilling operation is larger than conventional vertical drilling, making appropriate placement with regards to environmentally sensitive areas (streams, lakes, wetlands) important. But, horizontal drilling, allows multiple closely spaced wells to be drilled on a single well pad location, thereby reducing the number of pads necessary to develop unconventional resources.

The combination of horizontal drilling and high volume, multi-stage hydraulic fracturing also constitutes a shift in scale in the mid-Atlantic gas development operations. Although these methods are not altogether new to oil and gas development and hydraulic fracturing techniques have been used since the late 1950s in conventional development, in combination they have not been used broadly throughout the Appalachian shale gas region. The process of horizontal drilling and hydraulic fracturing of deep shale gas formations requires large quantities of drilling materials to be stored on site. This is especially true when multiple horizontal wells are being drilled on the same pad. Fresh water use for unconventional shale gas development varies, but approximately 11.5 to 19 million liters of water are required to develop a single horizontal gas well within the Marcellus reservoir [Arthur et al., 2010; DOE and NETL, 2009]. In the Susquehanna River Basin (SRB) in Pennsylvania, this translates to a projected peak demand of 
31.8 million liters per day [DOE and NETL, 2009]. In perspective, thermoelectric power generation consumptively uses almost 570 million liters per day [Arthur et al., 2010], however water withdrawals for shale gas development remain significant compared to conventional drilling practices (Table 1). Timing and rates of withdrawals, combined with the transportation and storage of water, present challenges for the industry. The volumes of chemicals in the hydraulic fracturing process, along with increased generation of wastewater also increase with unconventional gas development. Transportation, use and storage of wastewater can result in environmental impacts from accidental releases. The random nature of these events makes them difficult to predict and evaluate but will ultimately lead to impacts at the watershed scale.

The rapid increase of shale gas development in the mid-Atlantic region has brought concerns to regional drinking water supplies that involve shallow groundwater reservoirs. These concerns often have the potential to ramify across communities, as even the perceived risk of groundwater contamination can lead to significant decreases in home values [Muehlenbachs et al., 2012]. Great importance is given to potable aquifers, particularly in rural areas where households are dependent on groundwater for domestic use. In West Virginia and Pennsylvania, for example, this constitutes 42 and 50\% of state residents, respectively [Chambers et al., 2012; Fleeger, 1999]. Groundwater used for potable drinking water supplies is extracted primarily from drinking water wells that often lack recommended construction standards, which increase susceptibility to contamination related events [Boyer et al., 2012]. Large gas productions in formations, such as the Marcellus, are attributed to continuous advancements in the gas extraction process. However, thousands of properly and improperly plugged and abandoned legacy oil and gas wells exist throughout the mid-Atlantic region [Gass et al., 1977], which draw attention to gas well casing and cementing issues. Cementing measures serve to form a barrier 
around gas well casings, engineered to provide geologic separation of water and gas baring zones. Proper design and installation are vital in protecting freshwater aquifer integrity as their role is to keep contaminants, such as stray gas, from migrating to the surface [Harrison, 1985]. This is especially important during the production phase of the well when high gas pressures are present in the well column.

The development of unconventional shale gas reservoirs undoubtedly will contribute to environmental impacts of both surface and subsurface water resources. These impacts can occur at various stages of well development, as well as cumulatively throughout the gas extraction process. Three phases of the unconventional shale gas development process are discussed below to provide the necessary information for understanding potential impacts to water resources. These are the infrastructure development process; the drilling and casing process; and the hydraulic fracturing process.

\subsection{2 - Infrastructure development}

Early stages of the gas development process are in many ways similar to traditional construction activities associated with road and site infrastructure. Where infrastructure does not already exist, development begins with the removal of vegetation from the site. Heavy equipment is used to remove and stockpile topsoil for site reclamation after drilling and completion, and extraction of natural gas. Activities occurring in steep terrain often require large cut and fills to establish adequately-sized roads and well pads. Generally gravel is brought on site and used in road construction. In remote areas, access roads often serve as right of ways for gas gathering and transmission lines and are frequently accompanied by water lines used for drilling and hydraulic fracturing. Stormwater control devices, often in the form of ditches, 
sumps and silt berms are used to manage runoff and control sediment transport. This is especially important for transmission lines that often run in long lateral spans.

Infrastructure necessary for natural gas development generally consists of access roads and storm water control systems, drilling pads, water impoundments, compressor stations, and gas transmission lines. Surface disturbance for horizontal well operations at the site scale are generally larger than vertical operations, but the use of horizontal drilling techniques for the extraction of shale gas in the mid-Atlantic will ultimately reduce land disturbance, as more wells can be drilled from a single pad location. The primary difference between conventional and unconventional operations at the surface is the number of wells per drill pad. This equates to the construction of 4 horizontal wells drilled from a single pad location to fully develop a production unit (259/hectares) compared to 16 conventional vertical wells, that each would require separate infrastructure [DOE and NETL, 2009].

\subsection{3 - Drilling and casing process}

Gas well construction and integrity guidelines outlined by the American Petroleum Institute (API), describe the basic components required for drilling a typical horizontal well used in unconventional gas extraction. Fluid rigs use water-based drilling fluid to circulate drill cuttings, stabilize the borehole, and cool and lubricate the drill bit, [DOE and NETL, 2009; NYDEC, 2011]. The vertical portion of an unconventional drilling operation mirrors that of conventional drilling except that the volume of produced drill cuttings and duration of operations are much greater for unconventional wells. Drilling operations often begin with rigs capable only vertical in capacities. These "top hole" rig operations are much smaller and more mobile than those used in horizontal operations (triples) but are just as effective in drilling and 
placement of the first series of casing. The drilling and placement of casing in both vertical and horizontal operations includes:

1. Conductor Casing to depths of approximately $18 \mathrm{~m}$ designed to provide structure for the well by holding back loose surface material and shallow sub-surface water.

2. Surface Casing to depths $30 \mathrm{~m}$ below the lowest potable aquifer designed to completely isolate groundwater by providing steel and cement barriers between aquifers and additional casing strings.

3. Intermediate Casing string which serves to isolate geologic formations from the production casing to seal off other hydrocarbon baring zones and abnormal pressures formed at depth.

4. Production Casing which runs from surface through the length of the lateral or the horizontal portion of the well to isolate the target formation.

Drilling and placement of each casing string occurs inside the previous casing (Figure 5).

Centralizers, metal sleeves placed on the outside of the well casing, are placed at specific intervals to insure proper cement thickness in the annular space between casings. The proper cementing of surface casing is an important step in the construction of a natural gas well, as it protects aquifers from drilling mud and production fluids [DOE and NETL, 2009]. Full cementing of the surface casing is recommended by API and is required by most states nationwide [GWPC, 2009]. Intermediate casings often are used to further isolate subsurface geology and are followed by drilling of the production hole and placement of casing using a rig capable of horizontal operations. The production casing runs from surface through the length of the lateral or the horizontal portion of the well. The kick off point, located approximately $152 \mathrm{~m}$ above the target formation depth, serves as the start of the horizontal, which can extend several thousand feet. Cement is pumped into the outside of the production casing approximately $152 \mathrm{~m}$ above the formation to be stimulated. This allows for proper isolation of the target formation. 
After testing of the casing and cementing is complete, the well is ready for stimulation, typically in the form of hydraulic fracturing.

\subsection{4 - Hydraulic fracturing process}

The use of hydraulic fracturing, often termed "fracing", has been a common practice in the economic development of natural gas for over 50 years [DOE and NETL, 2009]. This process constitutes an unconventional gas extraction technique to make these wells economically feasible. Porosity variances result in differences in unaided gas flow. Hydraulic fracturing consists of injecting slurry, composed of water, sand, and chemicals under high pressure, into the target formation to fracture the bedrock and release the stored hydrocarbons. In unconventional operations, hydraulic fracturing is used to increase permeability of shale formations and stimulate gas flow after drilling and casing are complete. In horizontal hydraulic fracturing, laterals can span several thousand feet. In order to maintain sufficient down-hole pressures during the operation the process is completed in stages, usually 150 to $300 \mathrm{~m}$ in length. The primary constituents of a hydraulic fracturing operation (making up over $99 \%$ of the down-hole mixture) are water and sand [DOE and NETL, 2009]. Water allows pressure to be placed on the formation to perform the treatment. Generally 11.5 to 19 million liters of water are used for a traditional horizontal fracture operation; however, water use for Marcellus operations can be as high as 15 to 30.2 million liters [Arthur et al., 2010; DOE and NETL, 2009]. The primary difference between hydraulic fracturing of unconventional horizontal operations as opposed to those that occur in conventional vertical operations is the volume of water and chemicals used for horizontal operations and, therefore, wastewater generated. The volume of water required is dictated by the geologic formation properties, the well depth, and length of the lateral portion of the well. Sand is used as a proppant in the hydraulic fracturing process; it is distributed deep into 
the formation to support or prop open the newly created fractures. Chemical additives including surfactants, gelling agents, $\mathrm{pH}$ adjusters, corrosion inhibitors, and biocides, and make up less than $1 \%$ of the volumetric fracture mixture. When pressure is released from the formation, wastewater, referred to as flowback, is recovered. Consumptive use of water used in the hydraulic fracturing operations can be upwards of $90 \%$, although typically between $10-70 \%$ is recovered at the initial flowback period [American Petroleum Institute, 2010; Penn State Extension, 2009]. Consumptive use, which is defined as water not directly returned to the system from which it came [Penn State Extension, 2009], also can occur when water is withdrawn or discharged in a different basin from which it was extracted. Formation contraction occurs after a hydraulic fracturing operation, generating flowback waters; however the presence of sand prevents contraction from relapsing completely, and serves to prop open the newly created fissures, allowing gas to flow. Lesser volumes of wastewater are generated after the initial flowback period, but flowback occurs over the lifetime of the well. On-site treatment and reuse of wastewater in the Marcellus region represented 56\% of total water disposal in 2011 [Lutz et al., 2013]. Wastewater is stored temporarily on site in large portable tank trucks known as frac tanks, and then disposed by injection into class II injection wells, which are geologically isolated compartments used for the storage of waste, or treated and discharged at wastewater treatment facilities [Arthur et al., 2008].

\section{4 - Impacts to water resources}

The scale of unconventional gas development operations in the mid-Atlantic region has brought increased attention to its environmental impacts, especially relative to water resources. This responsiveness arises from the increased industrialization of the hydraulic fracturing process; increased number of environmental accidents related to the increased rate of drilling 
activities since 2008; and the proximity of these relatively untapped, unconventional shale reservoirs to major metropolitan areas [Vaughn and Pursell, 2010]. In Pennsylvania, which is at the heart of current Marcellus shale development, an analysis of the Department of Environmental Protection Notices of Violations (NOV) between January 2008 and August 2011 by Considine, [2012] showed that 1,144 NOVs were issued over 845 separate events. Of these violations, 25 were classified as major events that included major site restoration failures, serious contamination of local water supplies, major land spills, blowouts and venting, and stray gas migration. When evaluated against the 3,533 wells drilled during this 44 month reporting period, the probability of a major environmental event occurring was $0.7 \%$.

Rahm and Riha, [2012] discuss the differences between deterministic (planned activities certain to occur) and probabilistic (accidental unplanned and uncertain events at a project location) impacts associated with Marcellus shale gas development. Significant focus has surrounded the mitigation of probabilistic impacts that occur as site-related incidents, most often in the form of accidental spills. However, collective deterministic impacts that will occur, such as natural gas infrastructure development, constitute a direct and often permanent change to the landscape. In small headwater catchments that are important for generating streamflow [Nadeau and Rains, 2007], these impacts alter many landscape attributes, such as soil, vegetation, and topography. Changes to these attributes ultimately alter watershed response, especially at the headwater scale, by modifying the components of the hydrologic cycle [Mohamoud, 2004]. Although these impacts can be described empirically, quantifying them with a physical model is often only partially successful and remains inherently difficult across scales in data-limited environments. Therefore, the remainder of this review focuses on both surface and subsurface influences associated with unconventional shale gas development. 


\subsection{1 - Surface impacts}

Transport of sediment and contaminants from natural gas production sites is the primary water quality concern of surface activities associated with gas development [Entrekin et al., 2011]. This is not necessarily surprising given that soil loss from construction sites average 200 ton $\mathrm{ac}^{-1} \mathrm{yr}^{-1}$ in the United States [Soil and Commission, 2002], and sedimentation is the single largest threat to the nation's water resources [Brady and Weil, 1996]. The Clean Water Act and its amendments regulate runoff and sediment for construction activities. However, there is a general lack of federal regulation applying to natural gas development and extraction, which has resulted in a lack of oversight of disturbance-related problems. Williams et al. [2008] investigated several gas well-pad sites in Denton County, Texas and found that sediment runoff was similar to that of standard construction sites. Results from ten storm events indicated that sediment runoff occurred at a greater rate and frequency at gas well-pad locations compared to reference sites. Based on calculations by Bishop. [2011], sediment in runoff for a 10,000 gas well-development scenario in New York would contribute a minimum of 80,000 tons of sediment per year into nearby waterways. However, derivations of these reported estimates of sediment were not explicitly outlined and can very significantly across various terrains, where site conditions often limit the ability to reduce slope length and gradient.

Controlling sediment losses associated with natural gas infrastructure can result in additional benefits aside from reducing sedimentation. Contaminants that attach to sediment particles also can be controlled with sediment control strategies [Faucette et al., 2005].

Petroleum spills from heavy equipment refueling, and chemical spills from drilling and hydraulic fracturing operations make containment at the well pad especially important. As well pad sizes and the volume of on-site chemical storage have increased with the adoption of multi-well and 
horizontal drilling practices, the risk of water contamination through erosion and sediment also increases.

Spills can also result in direct contamination of surface water bodies through overland flow or through transport via infiltration and shallow subsurface flow [NYDEC, 2011]. Questions remain regarding appropriate setback distances of natural gas infrastructure from surface water bodies (streams, lakes, wetlands) and groundwater wells. Boyer et al. [2012] suggested a 915-m setback distance for gas infrastructure from groundwater wells based on sampling conducted in the Marcellus shale regions of Pennsylvania; however there is a general absence of scientifically defensible evidence supporting this suggestion.

In the case of surface contamination, which can ultimately lead to infiltration impacts, the use of isotopes to detect these potential infiltration impacts remains among the most promising techniques. For example, strontium isotopes have been used successfully to trace coal bed natural gas (CBNG) produced water in to the hyporheic zone [Brinck and Frost, 2007]. Strontium isotopes currently are being employed in the Marcellus region to differentiate total dissolved solids (TDS) from multiple sources, which is important for tracing produced wastewater in the event of accidental release [Chapman et al., 2012].

\subsection{1 a - Water withdrawal impacts}

The impacts of shale gas development on water quantity are important, as water quality is inherently linked to water quantity. Surface water constitutes the primary source of withdrawals for gas development operations in the mid-Atlantic, although groundwater wells and municipal water supplies also are used [NYDEC, 2011]. The successful development of unconventional shale gas requires fresh water in both drilling and hydraulic fracturing operations, with a typical hydraulic fracturing operation using between 11.5 to 19 million liters [Arthur et al., 2010]. This 
demand is small compared to other uses (e.g. thermoelectric power generation) but remains substantial compared to conventional drilling practices (Table 1), particularly when considering that the demand for water in hydraulic fracturing operations occurs over relatively short durations. As previously mentioned consumptive use of hydraulic fracturing operations (water lost to the system) can be upwards of $90 \%$ and typically ranges between $10-70 \%$, whereas consumptive use of thermoelectric power generation is approximately 3\% [American Petroleum Institute, 2010; DOE and NETL, 2009; Penn State Extension, 2009] making these volumes comparable.

A county-level evaluation of surface water availability was conducted by Roy et al. [2005] outlining the sustainability of water withdrawals in the United States. Sustainability is defined as the ability to meet future water demands, given current status and trends of withdrawals, using existing water sources. This study provided a summary of the nation's largescale use of freshwater and included projected findings to the year 2025. The report identified three key areas that require further investigation including in-stream use requirements to maintain optimal habitat and beneficial uses, water storage and withdrawal capacity available, and more temporally detailed patterns of water use [Roy et al., 2005]. While these efforts to outline sustainability have been addressed, this evaluation did not consider increased withdrawals associated with unconventional gas development such as the Marcellus shale. This leads to uncertainty behind suitable estimates of water use for unconventional gas extraction in the mid-Atlantic region. This can be attributed to the rate at which development is occurring and sheds light on the deficiency of scientific investigation.

Concerns related to cumulative water withdrawals and subsequent streamflow reductions at the watershed scale include water quality impacts, aquatic impacts, and water availability for 
other uses. These can result from increases in stream temperature, effluent concentrations, and changes to stream geomorphology under altered flow regimes. Currently multi-state jurisdictional commissions in the mid-Atlantic region, such as the Susquehanna River Basin Commission, regulate pass-by-flows. Pass-by-flows are prescribed flow volumes that are required at a prescribed point downstream the entire time during which a withdrawal is occurring. In the Susquehanna River Basin, current pass-by-flow requirements are based on the 7Q-10, a common regulatory metric for lowflows. The 7Q-10 is the lowest average consecutive 7-day flow that would occur with a frequency or recurrence interval of once every ten years [SRBC, 2002].

New strategies have been proposed to regulate pass-by-flows to address summer lowflows as well as seasonal flow requirements that are threatened by withdrawals for gas development [DePhilip and Moberg, 2010; Rahm and Riha, 2012]. These can be important for species, such as brook trout (Salvelinus fontinalis) that have the potential to be impacted by changing flow regimes from water withdrawals in small catchments [Weltman-Fahs and Taylor, 2013].

\subsection{2. - Groundwater impacts}

\subsection{2a. - Surface driven groundwater impacts}

Recent publications, most notably Osborn et al. [2011], documenting localized groundwater contamination issues have sparked enormous interests in the potential threat of shale gas development to shallow groundwater resources. Potential impacts to groundwater resources can occur at each stage of unconventional gas development both in the form of vertical migration of contaminants and as the result of surface-driven activities. Examples of surface impacts include infrastructure development, which can lead to soil compaction issues resulting in 
overland flow instead of infiltration and recharge of shallow groundwater aquifers. Spills and leaks from construction equipment used to build access roads, drill pads, and pipelines have the potential to infiltrate shallow subsurface groundwater, resources that are important in maintaining streamflow and recharging shallow groundwater aquifers. Also of concern are leaks from the storage containers and holding ponds, accidental releases during transport of chemicals, and wastes generated during the drilling and hydraulic fracturing process. Although ground water withdrawals are not common, in cases where they do occur for gas development concerns relate to temporary depletion of aquifers that many rural households depend upon for potable water sources. These aquifers also contribute to baseflow, which sustains streamflow between storms and during dry conditions. Nonetheless, these surface activities conceptually identified above are not well documented. This is most likely due to the size and unpredictability at which these events occur and their actual detectability. In all watersheds, an evaluation of the surface and groundwater budgets and the interactions between surface and groundwater systems are important for preserving hydrologic conditions in these catchments [NYDEC, 2011].

\subsection{2b. - Subsurface driven groundwater impacts}

The process of gas well drilling itself poses risk to groundwater aquifers, most commonly in the form of short-term turbidity increases from aquifer penetration [NYDEC, 2011]. However, in Pennsylvania a study of water quality conditions in private water wells conducted by The Pennsylvania State University showed $40 \%$ of wells tested failed at least one Safe Drinking Water Act standard [Boyer et al., 2012] which most times were not previously known by the well owner. This demonstrates the importance of documenting current water quality conditions before gas well drilling occurs. In a statistical analysis of pre- versus post-drilling water chemistry, no major influences from gas drilling operations were observed in 233 residential 
groundwater wells, though one well did show an indication of increases in chemical constituents associated with the hydraulic fracturing process Boyer et al. [2012], but causation was not inferred. This was also the case for dissolved methane concentrations in 48 wells sampled both before and after drilling, another area of primary concern related to groundwater impacts from unconventional gas development. However, the study lacked isotopic analysis necessary for source determinations [Boyer et al., 2012]. By contrast, isotopic evidence was provided by Osborn et al. [2011] who documented methane contamination to drinking water wells in northern Pennsylvania and south eastern New York after natural gas extraction, but lacked the preliminary data to substantiate the findings. In both of these studies interpretations were limited by design.

\subsection{3 - Stray gas and fluid migration}

Methane $\left(\mathrm{CH}_{4}\right)$, the primary component of natural gas, is a common organic compound that has no natural color, odor or taste. Its vast known quantities (especially in shale formations) make it an attractive and recently revived source of energy. However, methane's explosive properties at concentrations between 5 and $15 \%$ by volume of air, and its potential asphyxiation hazard in confined spaces begets concern, especially in domestic water wells [Keech and Gaber, 1982]. The occurrence of dissolved methane in groundwater has been observed for several decades, and is often naturally present [Barker and Fritz, 1981; Mathes and White, 2006]. Conversely, stray gas migration from poorly constructed gas wells, abandoned legacy oil and gas wells that are common in the mid-Atlantic, and gas storage fields has been documented [DiGiulio et al., 2011; OHDNR, 2008; Osborn et al., 2011; Révész et al., 2010; Thyne, 2008]. Methane is found primarily in two forms, distinguishable only by their isotopic composition. Thermogenic methane, associated with deep sedimentary geological formations such as the 
Marcellus shale, forms when organic matter is subjected to heat and pressure over millions of years [Clark and Fritz, 1997]. This differs from bacteriogenic or biogenic methane which is derived from microbial metabolic progression commonly formed in shallower sources. By evaluating carbon isotope fractionation $\left(\delta^{13} \mathrm{C}\right)$ within $\mathrm{CH}_{4}$ along with comparing $\delta^{13} \mathrm{C}$ to suspected source material, a distinction between the two forms can be made [Osborn and McIntosh, 2010].

Instances where natural gas extraction has been suspected of contaminating groundwater, often in the form of stray gas migration, have led to case studies by state and federal environmental protection agencies. Several studies have documented evidence of increasing methane concentrations in shallow groundwater with proximity to gas wells, as well as temporal correlations with natural gas activity [DiGiulio et al., 2011; Osborn et al., 2011; Thyne, 2008]. In some cases, concentrations observed in drinking water wells exceeded hazardous levels $(28 \mathrm{mg} / \mathrm{L})$ established by the EPA. Natural gas exploration of the Pavillion, Wyoming gas field led to a study by the Environmental Protection Agency to identify potential groundwater contamination sources. The draft report suggests several sources of contamination, including evidence of enhanced methane migration and aquifer contamination resulting from natural gas development activities [DiGiulio et al., 2011]. Thyne. [2008] documented elevated chloride and methane in groundwater wells with temporal trends of increasing methane in groundwater samples that coincided with gas wells installed in the Mamm Creek gas field in Colorado. These incidents are not unique to the western settings - Osborn et al. [2011] documented systematic evidence of methane contamination of drinking water wells in the area of natural gas development in northern Pennsylvania and New York, which appeared to be attributable to gas well development based on the presence of thermogenic methane in the drinking water wells 
These studies have faced strong criticism for lack of baseline data (prior to gas well drilling) and lack of statistical evidence to support conclusions [Davies, 2011; Donato et al., 2009; Molofsky et al., 2011; WRI, 2012].

In another study, methane concentrations from more than 1700 water wells showed no proximal relationship of dissolved methane to oil and gas activities, but elevated methane levels in Pennsylvania were found to be highly correlated with topography, which can concentrate gas. Molofsky et al. [2011] suggests that the thermogenic signatures found by Osborn et al. [2011] are those indicative of shallower Upper and Middle Devonian deposits rather than that of the Marcellus shale. Also unclear in the findings by Osborn et al. [2011] are the potential mechanisms for gas migration, with lack of evidence to point to hydraulic fracturing [Davies, 2011]. This illustrates that even though evidence of contamination is provided, it cannot directly be linked to hydraulic fracturing or even to a specific gas well. This can become even more difficult when trying to target a specific operator within a specific location. In Bainbridge Township, Ohio, inadequate cementing behind the production casing in combination with high pressures on the well annulus (the concrete filled space between well casings) was suspected to have allowed gas migration into the local aquifer, which consequently resulted in a residential home explosion [OHDNR, 2008].

Gas storage fields also have been suspected contamination sources. This was most likely the case in Tioga County, Pennsylvania where isotopic analysis of methane in groundwater was similar to that of a nearby natural gas storage field [Révész et al., 2010]. Pathways for stray gas suggest the possibility of fluid migration, especially under natural and induced hydraulic head scenarios. Warner et al. [2012] reported preliminary evidence of this from elevated salinity, commonly associated with wastewater generated in the process of hydraulic fracturing, in 
shallower groundwater sources above the Marcellus shale. Groundwater geochemical signatures were similar to produced water from the Marcellus formation, suggesting connectivity to deeper formations from pre-existing pathways.

\subsection{3a - Transport pathways for gas and fluid migration from depth}

Inherent complexities concerning the relationship between hydraulic fracturing and direct impacts on shallow groundwater resources exist. Connection of deep shale formations to shallow groundwater aquifers via hydraulic fracturing is often thought to be impossible due to geologic separation and the mechanisms that govern gas accumulation and, therefore, extraction. Evidence to support this hypothesis has been established by research mapping hydraulic fracture height growth [Davies et al., 2012; Fisher and Warpinski, 2012]. However, instances of methane migration into regional groundwater aquifers have been linked to natural gas exploration [OHDNR, 2008; Osborn et al., 2011; Révész et al., 2010]. Possible pathways of contamination include natural faulting, casing and cementing problems, and previously opened and improperly plugged boreholes. Myers. [2012] provides a framework for major contamination pathways from shale layers to surface as advective transport through sedimentary rock, fractures and faults, and abandoned wells or open boreholes. He includes a conceptual flow scenario using MODFLOW with simulations indicating that fluids and contaminants, along with the displacement of brine water, have the potential to be released to near surface aquifers through comparatively decreased geologic travel times following hydraulic fracturing. However, the complex modeling approach used in this study renders estimates uncertain. Little to no data are available for post-analysis of hydrogeologic changes in shale properties. Myers. [2012] called for expanded monitoring to track contaminant movements and for the use of seismic studies to locate naturally faulted areas. 
Dusseault et al. [2000] outlined a conceptual model that explains slow gas migration behind gas well surface casings based on the shrinkage, strength and rigidity, and bonding properties of cement. There are several possible reasons for cement shrinkage. Autogenous shrinkage, which is due to volume reduction of original cement, is often associated with conservative systems such as mass concrete in dam interiors. Additives (such as silica flower) help to combat this volumetric reduction, but can also result in increased drying, causing shrinkage to become problematic once again. Occurring from flash setting and high curing temperatures, shrinkage can result from high salt content in cement slurries leading to osmotic dewatering. Strength and rigidity of cement properties are specifically addressed in API standards for oil and gas well construction and are not listed as a particular area of concern. However, the ability for well annulus to resist shear due to geologic compaction, heaving, and buckling over time has the potential to be significant. Circumferential (lying along the outskirts) fractures can occur over years or even decades. Cement bonding has difficulty adhering to many materials found at the cement-rock interface. The implications of this are that cement outside of casings may not always be sufficient to isolate geologic structures. This may provide flowpaths for gas and or fluid migration. Lacombe et al. [1995] discussed fluid flow and contaminant transport attributable to open conduits from leaky boreholes through geologic formations that otherwise had been considered isolated from each other. Three scenarios were considered using three dimensional flow and transport modeling. Lacombe et al. [1995] showed that leaky boreholes can transport contaminants into aquifers by changing the multi-aquifer / aquitard systems. Hydraulic head can be altered by the placement of new boreholes (groundwater monitoring wells, geologic research boreholes, and oil and gas exploration wells) into the aquifer 
and by waste injection, resulting in both downward and or upward movement of contaminants between otherwise isolated aquifers [Avci, 1994].

\section{5 - Management of drinking water resources}

As stated by Entrekin et al. [2011], quantifying the impacts of natural gas development on water resources remains inherently difficult due to the uncertainty behind location and timing of future drilling; this uncertainty is compounded by various levels of compliance required across state and local agencies, and the difficulty in identifying and distinguishing watershed impacts from previous anthropogenic activity. Better management of water resources requires an understanding of the interactions between surface and subsurface watershed processes, as well as other variables that contribute to difficulties associated with these multifaceted management approaches.

\subsection{1 - Conceptual model development}

Conceptual models can be useful tools in identifying potential water-related risks associated with unconventional shale gas extraction methods, particularly given large uncertainties and paucity of data, as well as lack of controlled experiments. Models that identify the potential surface water impacts of gas development activities to aquatic ecosystems and brook trout populations have been previously developed [Entrekin et al., 2011; Rahm and Riha, 2012; Weltman-Fahs and Taylor, 2013]. In order to address potential surface and subsurface effects on drinking water resources from unconventional shale gas development, a conceptual model developed from this review has been developed (Figure 6). The objective of this conceptual model is to identify knowledge gaps and provide a framework for resources managers to evaluate potential impacts of unconventional shale gas development. I have attempted to integrate surface and subsurface processes associated with natural gas development that have the 
potential to affect water resources. In this model natural gas development is broken into four major phases of the extraction process including infrastructure development, drilling, hydraulic fracturing, and flowback recovery / management. Each of these phases requires activities with potential consequences in the form surface and subsurface impacts. Model components were identified through this review and annotations simplify the process of finding material on specific subjects. Continuous effort in mitigating impacts from gas development are occurring and a comprehensive list of references was not the objective of this model however annotations reference key documents in this review which provide a starting point for information.

\subsection{2 - Knowledge gaps, research techniques, and management}

With increasing shale gas development come the potential for hydrologic impacts associated with each stage of the extraction process, which can occur at the site and watershed scale. It is impossible to predict all of the hydrologic impacts associated with gas development, as many occur as random events. Lack of understanding of the cumulative hydrologic impacts still exists, but understanding those effects is essential to guiding and improving the management of surface and groundwater resources. The following knowledge gaps identified by this review include:

1. Disturbance Effects- There is a long history of anthropogenic disturbance to the landscape in the mid-Atlantic region which currently contributes to water quality degradation. This phenomenon is often compounded by overlapping events that distort relationships between specific disturbance events and particular water quality incidents. We know that infrastructure, including access roads and storm water control systems, drilling pads, water impoundments, compressor stations, and gas transmission lines, will constitute a permanent impact to the landscape. These disturbances often occur in forested areas that have not been subjected to large-scale industrial activity. Therefore, 
documentation and characterization of disturbance from unconventional natural gas development, both spatially and temporally are necessary to provide a proper understanding of synergistic effects. This especially important in headwater catchments that are sensitive to these large-scale changes.

2. Temporal Studies- Due to the operative challenges associated with paired catchment studies, controlled experiments with adequate baseline analysis serve as an important tool for gas well development related operations, yet few of these studies have been conducted. Calls for more temporal studies of unconventional drilling practices across the United States have been suggested [Palacios, 2012] and are currently underway in the mid-Atlantic [Eisenhauer et al., 2012; USEPA, 2012; McPhillips et al., 2012; Mulder et al., 2012]. These studies should address the cumulative effects of natural gas development on water quality (surface and subsurface) and quantity. Although a small number of studies have been initiated, increasing the spatial distribution of these studies and incorporating various catchment sizes is imperative. Future research also should consider incorporating social and physical watershed characteristics, including population, topography, lithology, and vegetation differences throughout the Marcellus shale region. The use of stable isotope techniques is essential for investigations ranging from methane fingerprinting to tracing produced wastewater and will most certainly continue to play a large role in investigating contamination events [Brinck and Frost, 2007; Osborn and McIntosh, 2010; Osborn et al., 2011; Stahl et al., 1981]. Most importantly, evaluating and monitoring drinking water aquifer quality is essential for detecting potential contamination issues associated with natural gas development. 
3. Modeling Hydrogeology- The assumption that geologic separation between deep unconventional shale formations and shallow drinking water aquifers prohibits direct adverse impacts from unconventional gas development operations has led to controversy within the scientific community. Evidence exists that vertical migration from depth can occur, however, minimal information and focus are directed toward the potential transport pathways. The expansion and synthesis of hydrogeological data in these areas is necessary to further identify and mitigate potential transport of gas and fluid from depth as was described by Myers [2012]. These future studies should focus on geologically complex regions where gas extraction and protection of groundwater resources remain most difficult.

4. Wastewater Generation- The large volumes of clean water used in hydraulic fracturing operations necessarily generate large volumes of liquid waste. Treatment and disposal of fluid wastes create many challenges, because the chemical composition typically contains many hazardous chemicals - some derived from the fracing chemicals, and some that are released from mixture with the geologic layers which are of marine origin. Disposal options currently consist of wastewater treatment and release to surface water, class II wells, and recycling via reuse in future hydraulic fracturing activities. Although reuse of flowback remains the current best and most efficient economic and environmental option, final disposal will represent challenges for the industry when the rate of consumption from new hydraulic fracturing operations no longer exceeds wastewater generated. A life cycle analysis of wastewater generation, reuses, and final disposal would lead to important understandings and possible development of new techniques for better management efficiency. Waterless fracing technologies (GASFRAC) are also in 
continuous development and may reduce future water management operations currently necessary for unconventional shale gas development. 


\section{Section 3.0 - Baseline Characterization}

\section{1 - Introduction}

The recent application of unconventional extraction methods in the mid-Atlantic, namely horizontal drilling and multi stage hydraulic fracturing, has led to rapid development of shale gas formations in Pennsylvania and West Virginia. The Marcellus shale is foremost among shale reserves, and in places such as eastern Ohio abundant production from the Utica shale, another gas bearing shale formation, will ultimately lead to natural gas development region-wide. With this increase in unconventional shale gas development is the potential for cumulative impacts to surface waters. These impacts occur at each stage of the extraction process and have been documented at the site and watershed scale, as discussed in the previous chapter [Entrekin et al., 2011; Olmstead et al., 2013; Rahm and Riha, 2012]. Current literature also acknowledges past impacts to regional groundwater resources attributed to unconventional natural gas development [DiGiulio et al., 2011, Osborn et al., 2011; USEPA, 2010], as well as the potential impacts associated with shale gas development and evidence of aquifer contamination via vertical migration of fluid and gas from depth. Potential vertical transport mechanisms include open boreholes from abandoned oil and gas wells, wellbore casing and cement failure, and natural geologic fractures [Avci, 1994; Dusseault et al., 2000; Lacombe et al., 1995; Myers, 2012]. It should be noted, however, that most studies represent cases where evidence of groundwater contamination from natural gas extraction was questioned due to a lack of baseline water quality data prior to development.

Although research efforts are continuously advancing, the effects of unconventional shale gas development on water resources are poorly understood because of the lack of controlled preversus post-drilling monitoring; a consequence of the rapid development of shale formations. 
The complexity associated with regional surface and groundwater systems requires an approach capable of discerning the effects of shale gas development from prior and current impacts. The goal of this study is to establish a monitoring framework to discern the impacts of natural gas development on shallow drinking water resources. This framework will allow for directed efforts to identify the hydrologic impacts associated with shale gas development. The foundation of this framework is based in the use of isotopes and geochemistry to characterize surface and groundwater. Isotopic and geochemical methods are effective tools for fingerprinting regional water sources in areas of gas development [Mulder et al., 2012].

Various water testing strategies have been employed in oil and gas development regions, but resources available and objectives of sampling ultimately determine which constituents are selected for analysis. Constituents can be classified into several major categories including (1) gas hydrocarbons, (2) liquid hydrocarbons, (3) salts, (4) metals, (5) naturally-occurring radioactive materials, (6) volatile organic compounds, and (7) poly-aromatic hydrocarbons [Palacios, 2012], with each having its own specific health-related concerns. In this study, research efforts focus on the use of major ion, isotope geochemistry, and trace element analyses to address these constituent categories. Liquid hydrocarbons, volatile organic compounds, or poly-aromatic hydrocarbons are not addressed, nor is an evaluation of expected products of chemical interactions conducted, as baseline characterization requires only documentation of pre-contamination constituent levels [Palacios, 2012].

\section{2 - Application of major ions, isotope geochemistry, and trace metals to groundwater}

characterization

Major ions, in combination with isotopic analysis, are effective tools for fingerprinting water sources, as they act as tracers to elucidate trends or changes in hydrochemistry. Using 
major ions as contaminate tracers can be limiting due to natural processes, such as water-rock interactions which also influence hydro-chemical signatures [Clark and Fritz, 1997]. Stable isotopes can be included with ion analysis due to their conservative properties. Isotopes are atoms that differ only in their number of neutrons. Isotope fractionation leads to preferential selection of isotopes relative to their heavy or light counterparts. For example, during the process of bacterial methanogensis lighter carbon sources are preferentially selected, resulting in depleted $\delta^{13} \mathrm{C}_{\mathrm{CH} 4}$ signatures [Whiticar, 1999]. Isotopes are expressed in delta notation $(\delta)$ in permil units (\%o) as the ratio of heavy to light isotopes $(R)$, which is then expressed against a standard assigned by the International Atomic Energy Agency (IAEA).

$$
\delta_{\text {Sample }}=\left(\frac{R_{\text {Sample }}}{R_{\text {Standard }}}-1\right) * 1000
$$

Major ions and isotopic analysis are effective tools used to characterize groundwater chemistry and identify the impacts of unconventional gas development which are addressed in the aforementioned groups. These tools are discussed below in the context of constituent classifications.

\subsection{1 - Gas hydrocarbons}

A recent example of the hydrologic impacts associated with natural gas extraction in the mid-Atlantic is stray gas migration. Natural gas produced from conventional and unconventional formations is primarily made up of methane, which is most commonly found in two forms; thermogenic and biogenic. Thermogenic methane is associated with deep sedimentary geological formations, such as the Marcellus shale, and forms from thermal decomposition of organic matter under high pressures over geologic time frames [Clark and Fritz, 1997]. Biogenic methane results from the digestion of organic compounds, and is commonly associated with shallow groundwater systems [Clark and Fritz, 1997]. Distinguishing between these 
sources of methane is accomplished by using carbon and hydrogen isotopes $\left(\delta^{13} \mathrm{C}_{\mathrm{CH} 4}, \delta^{2} \mathrm{H}_{\mathrm{CH} 4}\right)$ to evaluate carbon isotope fractionation $\left(\delta^{13} \mathrm{C}\right)$ within $\mathrm{CH}_{4}$, along with comparing $\delta^{13} \mathrm{C}$ to the suspected source material [Osborn and McIntosh, 2010]. $\delta^{13} \mathrm{C}_{\mathrm{DIC}}$ also can be used to provide insight for the characterization of methane sources; enriched signatures (10 and 30\%o) can indicate a biogenic origin [Sharma and Frost, 2009; Sharma and Baggett, 2011; Whiticar, 1999].

Osborn et al. [2011] attributed thermogenic methane contamination in drinking water wells in northern Pennsylvania and southeastern New York to Marcellus shale development. Methane concentrations in drinking water wells increased with proximity to the nearest gas well resulting in several cases of potential explosion hazards, as determined by the EPA. However, this work has been heavily criticized due to a lack of pre-drilling water samples. Molofsky et al. [2011] suggested that the thermogenic signatures found by Osborn et al. [2011] are indicative of shallower Upper and Middle Devonian deposits rather than that of the deeper Marcellus shale formation. Molofsky et al. [2011] suggested that elevated methane levels in groundwater often are correlated with topography rather than the proximity to the nearest gas well. Mulder. [2012] describes the difficulties associated with using isotopes to distinguish methane sources, by identifying inconsistencies in the current literature (Table 2).

Stray gas contamination of drinking water aquifers has received attention due to methane's explosive nature at concentrations between 5 and $15 \%$ by volume of air and its potential asphyxiation hazard in confined space; a situation especially hazardous in the context of domestic water wells [Keech and Gaber, 1982]. These potential hazards illustrate the importance of characterizing baseline conditions in groundwater, and thus, was the primary goal of this study. Through an evaluation of dissolved methane concentrations and isotopic analysis in drinking water wells $\left(\delta^{13} \mathrm{C}_{\mathrm{CH} 4}, \delta^{2} \mathrm{H}_{\mathrm{CH} 4}\right.$, and $\left.\delta^{13} \mathrm{C}_{\text {DIC }}\right)$ I address these concerns. 


\subsection{2 - Salts (Major ions)}

The process of hydraulic fracturing used in unconventional development practices generates significant volumes of wastewater in the form of flowback (directly after the fracture operation), and produced water (water produced during production). Due to the interaction of injected water at depth and the marine origin of the shale formations in the mid-Atlantic region, the wastewater generated often contains high concentrations of dissolved constituents, indicated by TDS levels as high as 100,000 ppm [DOE and NETL, 2009]. Major ions can be used to differentiate the various water sources through the use of Piper or Stiff diagram as they graphically represent the chemistry of a water sample. Concentrations of major ions in groundwater aquifers used for drinking water sources are most often statistically different from those observed in flowback and produced waters generated during the hydraulic fracturing process [Palacios, 2012]. Therefore, major ions serve as excellent change detection tools. Chloride and sulfate are of particular interest as they are also secondary drinking water standards for drinking water quality [USEPA, 2009]. The major ions used is this study to characterize background water chemistry were major anions including fluoride, chloride, nitrite, bromide, nitrate, phosphate, and $\mathrm{NO}_{2}+\mathrm{NO}_{3}$ along with a measure of alkalinity.

\subsection{3 - Naturally-occurring radioactive materials}

Also of concern in produced water from the Marcellus shale and other deep formations are naturally-occurring radioactive materials (NORM), often in the form of radium. Commonly occurring isotopes of radium $\left({ }^{224} \mathrm{Ra},{ }^{226} \mathrm{Ra},{ }^{228} \mathrm{Ra}\right)$ all contribute to radioactivity in water [USGS, 2013 ] ${ }^{226}$ Radium and ${ }^{228}$ Radium are the longest lived, most common isotopes of radium, and therefore, are tested frequently in drinking water aquifers [Szabo et al., 1998]. The decay of uranium and thorium leads to the natural formation of radium [Szabo et al., 1998]. Levels of 
radium in Marcellus-produced waters range between 0 and 18,000pCi/L [Rowan et al., 2011]. Concerns relate to the mobility of radium into the shallow groundwater either through infiltration and percolation from accidental spills of wastewater, or potential vertical migration of formation waters.. Radium can affect human and animal health, so it is regulated by the EPA with a primary drinking water standard $(5 \mathrm{pCi} / \mathrm{L})$ (Table 3$)$. This makes documentation of radium levels present in drinking water previous to natural gas exploration imperative. ${ }^{226} \mathrm{Ra}$ and ${ }^{228} \mathrm{Ra}$ were analyzed for monitoring naturally-occurring radioactivity in groundwater aquifers in this study.

\subsection{4 - Metals}

Little information is available with regards to trace metal concentrations currently found in cuttings generated during the drilling process, especially in the Marcellus shale region. Palacios [2012] outlines several metals that can lead to potential health effects, which are associated with oil and gas flowback fluids. These include aluminum, antimony, arsenic, barium, beryllium, cadmium, chromium, copper, iron, lead, manganese, mercury, selenium, and silver. To identify the population of metal constituents in this study a full trace element analyses was conducted.

\subsection{5 - Water and sulfur isotopes}

Other tools that can be used to characterize surface and groundwater include stable isotopes of water $\left(\delta^{2} \mathrm{H}_{\mathrm{H} 20}\right.$ and $\left.\delta^{18} \mathrm{O}_{\mathrm{H} 20}\right)$ and sulfur isotopes $\left(\delta^{34} \mathrm{~S}_{\mathrm{SO} 4}\right.$ and $\left.\delta^{18} \mathrm{O}_{\mathrm{SO} 4}\right)$. Stable isotopes of water can be used to differentiate water sources found at various depths, which often differ in isotopic composition. For example, Rostron and Holmden. [2000] documented unique $\delta^{18} \mathrm{O}_{\mathrm{H} 20}$ and $\delta^{2} \mathrm{H}_{\mathrm{H} 20}$ signatures between aquifers, as well as regionally within aquifers in the Willston Basin, an area of hydrocarbon exploration near Midale Saskatchewan. These waters were found 
to differ significantly from each other, allowing them to be differentiated from drilling fluids that contained a mixture of chemicals and near surface water. This illustrates the utility of water isotopes which also can be used to distinguish between waters of shallow potable aquifers and those associated with flowback from the Marcellus shale formation.

Sulfur isotopes also can be used as tracers of water origin to differentiate water sources and provide an understanding of sulfate sources. This characteristic is essential to further describe local hydrologic systems, which in turn is necessary to provide the means to discern the effects of previous anthropogenic activity on the landscape, such as acid mine drainage from coal mining, which is common in many parts of West Virginia. Sources of recharge also can be traced by means of sulfate isotopes and include precipitation and runoff, both of which influence groundwater quality. These tools can be useful in the event of surface contamination events.

\section{3 - Methods}

\subsection{1 - Study area description}

Three unconventional gas development locations have been proposed near the Summit Lake campground (Figure 7). Our study is designed to address concerns related to this development through a baseline geochemical and isotopic assessment of water conditions as part of a pre- versus post-drilling investigation. The campground and Summit Lake are located in the Gauley Ranger District of the Monongahela National Forest, West Virginia. The 17.4-ha lake is located 12.9 kilometers from Richwood, West Virginia. It serves as a recreational fishery and is the supplemental water supply for the town of Richwood during periods of low flow when surface water withdrawals from the Cherry River are insufficient. Local geology plays important roles in groundwater resources, so geologic characteristics are important for describing sampling locations. Ralph MacDonald, a former Forest Geologist for the USDA Forest Service 
described the geology of Summit Lake in 1965 in order to establish potable water for the area. His depiction (Figures 11 and 12) illustrates surface exposures in the Summit Lake area, which are predominantly shales of the New River Group, Pottsville Series, and are Pennsylvanian in age. The upper slopes of the area are shales and sandstones of the Kanawha Group, also in the Pottsville Series. Structurally, Summit Lake is in the trough and flanks of the northeast trending Kovan Syncline. The prominent Webster Springs Anticline is approximately 1 mile northwest and parallels the Kovan Syncline.

Water samples were collected from five locations near the Summit Lake campground to identify potential end members of water chemistry. Two drinking water wells, a shallow groundwater spring, Summit Lake, and the Cherry River were sampled. Few groundwater wells exist due to the lack of access and the remoteness of the area. The aquifer formation of the drinking water wells evaluated in this study is of the New River Group, which is Pennsylvanian in age. Locations selected for sampling and analysis were based on criteria including frequency of use by campers and local residents, access, completeness of well records, and proximity to proposed drilling locations. All of the selected sampling locations serve as important water sources for campers and the local community, making it important to capture both surface and groundwater signatures before gas development takes place in the area. Figure 7 shows the proposed drilling sites in relation to sampling locations surrounding Summit Lake

\section{4 - Water sampling procedures}

Two primary objectives of this study were to, (1) develop a protocol that provides a framework for incorporating guidelines to access sampling locations, discussing the equipment necessary for sampling at each location, and systematizing the procedures used for sampling and analysis, and (2) collect and report surface and groundwater chemistry conditions at 5 locations 
through a hydro-chemical and isotopic analysis for use as a baseline for pre- versus post-drilling comparisons. Isotope samples collected at each sampling location included $\delta^{13} \mathrm{C}_{\mathrm{CH} 4}, \delta^{2} \mathrm{H}_{\mathrm{CH} 4}$, $\delta^{13} \mathrm{C}_{\mathrm{DIC}}, \delta^{2} \mathrm{H}_{\mathrm{H} 20}, \delta^{18} \mathrm{O}_{\mathrm{H} 20}, \delta^{34} \mathrm{~S}_{\mathrm{SO} 4}, \delta^{18} \mathrm{O}_{\mathrm{SO} 4},{ }^{226} \mathrm{Ra}$, and ${ }^{228} \mathrm{Ra}$. Samples for major ions and trace elements were also taken at each location. ${ }^{228} \mathrm{Ra}$ and ${ }^{226} \mathrm{Ra}$ are reported for Summit Lake and the groundwater wells, as the uncertainty values for other locations were larger than the actual reported values. This was also the case for methane as only one water well was found to have concentrations above detection limits necessary for isotopic analysis.

\subsection{1 - Groundwater samples}

Two groundwater wells located within the Summit Lake recreational area were chosen based on their proximity to proposed drilling locations. Both wells are outfitted with pitcher pumps that allowed water to be manually pumped from a drop pipe that extended into the well. For sampling purposes, water wells were accessed by lifting the well head (i.e., manual pump) from the casing and supporting it through the use of a block and beam system (Figure 8).

Groundwater wells were purged at a rate of approximately $6.3 \times 10^{-5} \mathrm{~m}^{3} / \mathrm{s}$ until 3 casing volumes were removed, using a Foltz portable pumping system (Figure 9) outfitted with a Teflon sampling line. Sample water was directed from the submersible pump using a panel mounted PTFE stopcock and collected using low-flow techniques outlined by Puls and Barcelona. [1996]. Casing volumes were determined from individual water levels, well depths (Table 4), and casing diameter $(15.24 \mathrm{~cm})$. Purging ensured that the sampled water was representative of the target aquifer and not standing water within the well that had been affected by evaporation or $\mathrm{CO}_{2}$ gas exchange. For sampling purposes, the pumping rate then was decreased to approximately $1.6 \times 10^{-5} \mathrm{~m}^{3} / \mathrm{s}$ to further decrease turbulent exchange. 
Water samples collected for cations and trace elements (ICP-Mass Spectrometry) were filtered with Whatman $0.45-\mu \mathrm{m}$ filters placed on $60-\mathrm{ml}$ Luer-Lok syringes rinsed with the sample. The filtered sample was collected in $125-\mathrm{mL}$ bottles with no head space and acidified to $1 \% \mathrm{v} / \mathrm{v} \mathrm{HNO}_{3}$, capped, and kept cool and sheltered to preserve the sample composition. Water samples collected for anions (Ion Chromatography) were similarly syringed filtered in 60-ml collection bottles and capped with no headspace without acidification. Water isotopes $\left(\delta^{2} \mathrm{H}_{\mathrm{H} 20 \text {, }}\right.$ $\delta^{18} \mathrm{H}_{\mathrm{H} 20}$ ) were collected in $25-\mathrm{mL}$ glass vials and capped with no headspace. Dissolved methane samples $\left(\delta^{13} \mathrm{C}_{\mathrm{CH} 4}, \delta^{2} \mathrm{H}_{\mathrm{CH} 4}\right)$ were collected in 5 gallon buckets which had been rinsed and filled with sample water. A methane pre-rinsed (with sample water) methane sample bottle was submerged in the bucket with the Teflon sample hose inserted inside. After each methane sample bottle was fully flushed with sample water (equivalent to 3 bottles), the hose was removed and the sample bottle was quickly capped underwater to prevent outgassing. Sulfate isotopes $\left(\delta^{34} \mathrm{~S}_{\mathrm{SO} 4}, \delta \mathrm{O}_{\mathrm{SO} 4}\right)$ were collected in 1-L polyethylene bottles that were opened, filled, and capped under water with no headspace. Sulfate samples were processed at the West Virginia University Stable Isotope Laboratory. Radium samples were collected in 1-L polyethylene bottles provided by Test America. Samples were filled and capped under water with no headspace and shipped to Test America within 48 hours of collection. The $\delta^{13} \mathrm{C}_{\mathrm{DIC}}$ samples were syringed filtered into $25 \mathrm{~mL}$ glass vials with no headspace using Whatman $0.45-\mu \mathrm{m}$ filters on 60 $\mathrm{mL}$ syringes. Between two and three drops of the astringent benzalkonium chloride was added to the bottom of each vial to preserve the sample. All $\delta^{13} \mathrm{C}_{\mathrm{DIC}}$ samples were wrapped with parafilm around the vial lid and placed on dry-ice for shipment to the West Virginia Stable Isotope Laboratory. Following sampling, all field equipment was cleaned in standpipes constructed for each specific well using a detergent and deionized water rinses. A chlorine shock 
treatment also was used at each well location, as is customary and was recommended by the Forest Service engineers prior to replacing the well heads.

\subsection{2 - Shallow spring samples}

Spring water samples were collected from a shallow drinking water spring located in the Summit Lake Campground (Figure 8). A $5 \mathrm{~cm}$ pipe feeding the spring box was outfitted with a quick connect coupler and pipe flange (Figure 10), which effectively forced flow through the Teflon sampling line. Discharge from the spring outflow was directed into a 5-gallon bucket for 60 seconds, at which time the volume was measured to determine discharge. The average of three consecutive measurements was $6.78 \times 10^{-5} \mathrm{~m}^{3} / \mathrm{s}$. The Teflon sampling line was run to a panel mounted PTFE stopcock to control and direct flow. Flow was diverted into a flow-through chamber connected to a 556 YSI handheld multiparameter instrument, calibrated with standard buffers and solutions, for determination of field $\mathrm{pH}$, conductivity, dissolved oxygen, and temperature. These parameters were monitored until three consecutive measurements were within $10 \%$ of each other before the samples were taken.

\subsection{3 - Surface water samples}

Surface water samples were collected from Summit Lake and the North Fork of the Cherry River (-80²6.541', $38^{\circ} 13.895^{\prime}$ NAD 1983 UTM Zone 17N) (Figure 8). These samples were used to provide a one-time measure of surface water chemistry in the study area. Lake samples were taken at a depth of approximately $30.5 \mathrm{~cm}$ near the end of the dock near the public boat access. Samples from Cherry River were taken from a meandering, wide, shallow stream dominated by riffles at a small stretch where flow was concentrated to the left edge of the stream channel. Streamflow was generally laminar, with only a small eddy on the left bank. 


\section{5 - Baseline characterization of water chemistry}

Isotope samples collected for characterization of water sources included $\delta^{13} \mathrm{C}_{\mathrm{CH} 4}, \delta^{2} \mathrm{H}_{\mathrm{CH} 4}$, $\delta^{13} \mathrm{C}_{\mathrm{DIC}}, \delta^{2} \mathrm{H}_{\mathrm{H} 20}, \delta^{18} \mathrm{O}_{\mathrm{H} 20}, \delta^{34} \mathrm{~S}_{\mathrm{SO} 4}, \delta^{18} \mathrm{O}_{\mathrm{SO} 4}$, and Radium. Isotopes reported for all sampling locations consist of $\delta^{13} \mathrm{C}_{\mathrm{DIC}}, \delta^{2} \mathrm{H}_{\mathrm{H} 20}$, and $\delta^{18} \mathrm{O}_{\mathrm{H} 20} . \delta^{13} \mathrm{C}_{\mathrm{CH} 4}$ and $\delta^{2} \mathrm{H}_{\mathrm{CH} 4}$, were analyzed at one location where enough dissolved methane $(1.1 \mathrm{mg} / \mathrm{L})$ was present. Radium samples were collected, analyzed and are reported for Summit Lake, USFS-9913048 well and USFS-9913010 well.

Presented below are results, including analytical techniques, which are compared to constituents, outlined by the EPAs National Secondary Drinking Water Standards for salts and $\mathrm{pH}$. Several of these constituents represent key indicators for detecting changes in water chemistry in the event of an accidental release of wastewater or chemicals used in the hydraulic fracturing process [Palacios, 2012]. Also provided are the isotopic signatures and a discussion of the $\delta^{13} \mathrm{C}_{\mathrm{CH} 4}$ and $\delta^{2} \mathrm{H}_{\mathrm{CH} 4}$ signatures analyzed in one groundwater sample. Analyses of trace metals were also conducted at each sampling location, which are also compared to Secondary Drinking Water Standards (Table 6), to further characterize the system (Tables 7-11). Three important groundwater storage reservoirs are represented in these findings: shallow groundwater aquifers used for dinking sources, a spring representing shallow subsurface water, and surface water that may ultimately interact with these sources.

\subsection{1 - Alkalinity}

Alkalinity is the capacity of water to neutralize an acid and is often expressed in $\mathrm{mg} / \mathrm{L}$ as $\mathrm{CaCO}_{3}$. In general, alkalinity is influenced by water rock interactions but can also be influenced by wastewater, which often has higher concentrations of nutrients and ions. In this study alkalinity was determined using acid based titration methods. Through collaborations with the 
USGS a Hach digital titration was used to determine alkalinity values for both Summit Lake and the shallow spring location. Alkalinity was calculated using the formula (USGS titration sheet):

$$
\text { Alkalinity }\left(\mathrm{mg} / \mathrm{L}_{\text {as }} \mathrm{CaCO}_{3}\right)=50044(\mathrm{~B})\left(\mathrm{C}_{a}\right)(\mathrm{CF}) / V_{s}
$$

Where:

$\mathrm{B}=$ volume of acid titrant added from the initial $\mathrm{pH}$ to the bicarbonate equivalence point (near $\mathrm{pH} 4.5)$, in milliliters. To convert from digital counts to milliliters, divide by $800(1.00 \mathrm{~mL}=800$ counts) $\mathrm{C}_{\mathrm{a}}=$ concentration of acid titrant, in milliequivalents per milliliter

$\mathrm{CF}=$ Hach cartridge correction factor

$\mathrm{V}_{\mathrm{s}}=$ volume of sample, in milliliters

In-field digital titration was not available for the remainder of sampling locations;

therefore, these samples were collected, parafilm wrapped, stored on ice, and analyzed within 48 hrs at the West Virginia University Soil Science Laboratory. Concentrations were calculated using the USGS Web-based Alkalinity Calculator [USGS, 2012].

\subsection{2 - Major ions and trace metals analysis}

Major ion and trace metal analyses were conducted at Geoscience Laboratories in Ontario Canada using Inductively Coupled Plasma Mass Spectrometry (ICP-MS) and Ion chromatography (High Pressure Liquid Chromatography (HPLC)). ICP-MS is a mass spectrometry technique used for detecting metals at low concentrations by ionizing a sample with inductively coupled plasma. During this process a mass spectrometer is used to separate and measure ions. This highly sensitive technique allows for most of the elements in the periodic table to be determined. Because defining a narrow list of parameters for metals was difficult at the time of sampling, a full trace elements suite was conducted. However, at GeoLabs Canada this analysis excludes the major elements of sodium, magnesium, potassium, and calcium (Cations). These very important major elements require additional analysis; at Geo Labs Canada specifically, Inductively Coupled Plasma-Atomic Emission Spectrometry (ICP-AES). 
This realization was made after analysis had taken place and samples were discarded.

Unfortunately these major elements were not analyzed in this study, which precluded the use of a Piper or Stiff diagram and an ion mass balance.

HPLC is an analytical technique used for determining major anions including bromide, chloride, fluoride, total nitrogen, nitrite, nitrate, phosphate, and sulfate. This method can generally be described as the separation of a mixed sample into its individual constituents through the use of pumps that pressurize the sample, passing it through a column filled with sorbent (material used to absorb liquids). The interaction of the sample with the sorbent particles leads to its separating it into its individual analytes.

\subsection{3 - Isotopic analysis for methane, water, sulfur, and radium}

Isotopic analysis was conducted at West Virginia University Stable Isotope Laboratory, Test America (Pittsburgh PA) and Isotech Laboratories INC, (Champaign IL). Stable isotopes of water and DIC were analyzed using a Finnigan Delta Advantage continuous flow isotope ration mass spectrometer (IRMS) with the ThermoQuest Finnigan GasBench II device at WVU Stable Isotope laboratory. Reproducibility and accuracy were assessed by duplicate analyses of samples and internal lab standards (Hawaiian Spring, Eldorado and Morgantown tap), and was better than $0.2 \%$ for $\delta^{18} \mathrm{O}_{\mathrm{H} 2 \mathrm{O}}$ and $\delta^{13} \mathrm{C}_{\mathrm{DIC}}$, and $0.5 \%$ for $\delta^{2} \mathrm{H}_{\mathrm{H} 2 \mathrm{O}}$. All $\delta^{2} \mathrm{H}_{\mathrm{H} 2 \mathrm{O}}, \delta^{18} \mathrm{O}_{\mathrm{H} 2 \mathrm{O}}$ and $\delta^{13} \mathrm{C}_{\text {DIC }}$ values are reported in per mil (\%o) relative to the international standards V-SMOW (Standard Mean Oceanic Water) and V-PDB (Pee Dee Belemnite), respectively. ISODAT 3.0 software then was used to analyze a chromatogram, which displays lab reference and sample peaks. Methane and radium were determined at Isotech Laboratories INC, Champaign IL. It should be noted that pre-processing (precipitating out sulfate) of $\delta^{34} \mathrm{~S}_{\mathrm{SO} 4}$ and $\delta^{18} \mathrm{O}_{\mathrm{SO} 4}$ samples rendered 
concentrations too low to gather enough precipitate for analysis. Therefore, this analysis could not be conducted and $\delta^{34} \mathrm{~S}_{\mathrm{SO} 4}, \delta^{18} \mathrm{O}_{\mathrm{SO} 4}$ signatures are not reported.

\section{6 - Results and discussion}

\subsection{1 - Methane concentrations and signatures in groundwater}

Two groundwater wells located within the Summit Lake recreational area were selected for sampling and analysis. Well logs and a geologic map/cross section of the study area (Figure 11 and 12) place the wells sampled in the New River formation group and Pennsylvanian in age. Documenting baseline methane concentrations and composition was a primary goal of this study, since pre- versus post-drilling analysis of methane concentrations and isotopic signatures are seldom established. Groundwater sampled from the USFS-9913010 well had a high enough methane concentration (1.1mg/L) for isotopic analyses. $\delta^{13} \mathrm{C}_{\mathrm{CH} 4}$ and $\delta^{2} \mathrm{H}_{\mathrm{CH} 4}$ concentrations for this well were -57.46 and $-175.0 \%$, respectively (Table 12). Isotopic signatures found in this well indicate a microbial origin, which can result from the reduction of $\mathrm{CO} 2$ or acetate fermentation. Since the sample size of this study was low, values are brought into context with previous and ongoing work in the surrounding area. Across West Virginia, Mathes and White [2006] documented methane concentration in approximately 97 water wells that had their sources in Pennsylvania aged water-bearing rocks. Forty-nine wells had methane concentrations in excess of $1 \mathrm{mg} / \mathrm{L}$, and 11 were in excess of the federal recommended action level $(28 \mathrm{mg} / \mathrm{L})$. Concentrations found in Greenbrier County, in which Summit Lake is located, and the surrounding area were generally low in concentration $(<1 \mathrm{mg} / \mathrm{L})$, with only a few wells showing concentrations between 1 and $10 \mathrm{mg} / \mathrm{L}$. However, Mathes and White [2006] did not determine a source of methane using isotopic techniques. Mulder. [2012] sampled 25 groundwater wells that represented Pennsylvania aged water-bearing rocks in northeastern West Virginia and found only 
2 wells with methane concentrations above $10 \mathrm{mg} / \mathrm{L}$. Isotopic techniques for source determination showed thermogenic origins. It should be noted that other factors play a role in isotopic signatures of methane, such as topographic position [Molofsky et al. 2011]. Geologic age and aquifer formation are used for comparison in this study, as it represents a geographically simple study design that does not encompass various potential factors represented in more geographically expansive studies.

\subsection{2 - Isotopic signatures of sampling locations}

Groundwater samples collected from USFS-9913048 and USFS-9913010 have negative $\delta^{2} \mathrm{H}_{\mathrm{H} 20}$ values of -65.31 and $-61.86 \% \mathrm{~V}$-SMOW and $\delta^{18} \mathrm{O}_{\mathrm{H} 20}$ values of -10.54 and $-9.87 \%$ VSMOW, respectively (Table 12 ). $\quad \delta^{13} \mathrm{C}_{\text {DIC }}$ had compositions of $-14.23 \%$ V-PDB for the USFS9913048 well and -13.21\%o V-PDB for USFS-9913010 well. Samples collected from the shallow spring location have negative $\delta^{2} \mathrm{H}_{\mathrm{H} 20}$ signatures of -65.64\%o V-SMOW and $\delta^{18} \mathrm{O}_{\mathrm{H} 20}$ values of -10.74 V-SMOW, which are similar to those found at the drinking water wells (Table 12). Compositions $\delta^{13} \mathrm{C}_{\mathrm{DIC}}$ values were highest among all locations at the shallow spring source (USFS-SP), with compositions of -16.62\% V-PDB (Table 12).

Surface water samples collected from Summit Lake had negative $\delta^{2} \mathrm{H}_{\mathrm{H} 20}$ signatures of $-53.51 \%$ V-SMOW and $\delta^{18} \mathrm{O}_{\mathrm{H} 20}$ values of -8.52 V-SMOW (Table 3). Samples collected from the Cherry River had $\delta^{2} \mathrm{H}_{\mathrm{H} 20}$ signatures of -54.91\% V-SMOW and $\delta^{18} \mathrm{O}_{\mathrm{H} 20}$ values of $-8.45 \mathrm{~V}$ SMOW (Table 12). $\delta^{13} \mathrm{C}_{\mathrm{DIC}}$, values for Summit Lake were the lowest of all sampling locations (6.56\% V-PDB). Slightly higher values for $\delta^{13} \mathrm{C}_{\mathrm{DIC}}(-6.87 \% \mathrm{~V}-\mathrm{PDB})$ were found in the Cherry River sample. Maximum contaminant levels for radioactive elements (including radium) are outlined by the EPA in the Primary Drinking Water Standards (Table 3). Radium values were found at very low concentrations and in most cases were below detection limits. Combined 
${ }^{226} \mathrm{Ra}$ and ${ }^{228} \mathrm{Ra}$ concentrations must exist below $5 \mathrm{pCi} / \mathrm{L}$ to meet regulatory standards, and the maximum contaminant level goal for drinking water as outlined by the EPA is $0 \mathrm{pCi} / \mathrm{L}$. Radium values were found to be below the EPA regulatory action levels for all locations and considerably lower than potential levels for shale gas wastewaters, which can exist upwards of $18,000 \mathrm{pCi} / \mathrm{L}$.

\subsection{3 - Geochemical indicators, $\mathrm{pH}$, and trace metals}

Little information is present about trace metal concentrations found in flowback and produced waters generated during the drilling process, especially in the Marcellus shale region. Palacios [2012] outlines metals that have been associated with oil and gas flowback fluids that, when found in drinking water, can lead to potential health effects. These constituents include aluminum, antimony, arsenic, barium, beryllium, cadmium, chromium, copper, iron, lead, manganese, mercury, selenium, and silver. In this study focus is given to both drinking water wells and the spring location, as they serve as direct sources of drinking water for Summit Lake. Results from trace metal analyses show that constituents outlined above with major health effects were found at concentrations below EPA maximum contaminant levels at all sampling locations. However, two out of three constituents exceeded secondary drinking water standards at one location. Iron and manganese from the USFS-9913010 well were $>1.70 \mathrm{mg} / \mathrm{L}$ and $0.15 \mathrm{mg} / \mathrm{L}$, respectively. PH levels (Table 4) were also was outside the range of secondary drinking water standards at these sampling locations which represent direst sources of drinking water. Table 5 shows secondary drinking water standards recommend by the EPA. Most anions were below detection limits (*nd). Table 13 lists these constituents which include fluoride, chloride, *nitrite, *bromide, nitrate, *phosphate, and $* \mathrm{NO}_{2}+\mathrm{NO}_{3}$ were not detected (*nd). Chloride, sulfate, and fluoride were all found at levels below that of secondary drinking water standards. Attention to 
monitoring these constituents throughout the gas development process should be a priority and considered imperative in future sampling campaigns. This reporting of associated water chemistry values serves as the foundation from which to base future research efforts targeting water quality in the face of gas development in the Summit Lake recreational area.

\subsection{4 - Concluding remarks}

In this study, geochemical and isotopic techniques were used to establish baseline water chemistry conditions for water resources near Summit Lake, West Virginia. Two drinking water wells, a shallow spring, Summit Lake, and the Cherry River were sampled, as they all represent direct and indirect sources of drinking water used by campers and the local community. This sampling effort initiates one of the first pre- versus post-drilling unconventional gas development experiments on water quality, which was motivated by the proposed shale gas development in the Monongahela National Forest. A number of outcomes emerged from this study: namely the documentation of methane in one groundwater well and characterization of its isotopic signature. Although concentrations were low, isotopic analysis of methane was indicative of microbial origin and not suggestive of deep formation migration. In the same well, iron, manganese, and $\mathrm{pH}$ exceeded the range of suggested secondary drinking water standards established by the EPA. Although several limitations of this study exist, it serves as a foundation for future studies investigating the potential water quality issues associated with shale gas development that are likely applicable to the greater Marcellus region. 


\section{Section 4.0 - Thesis Implications and Overall Conclusions}

\section{1 - Introduction}

The purpose of this study was to elucidate potential impacts to water resources from unconventional shale gas development. This study focuses on three major objectives including (1) a comprehensive literature review surrounding the current state of understanding about natural gas extraction and its potential to impact drinking water sources; (2) the development of a sampling protocol that outlines equipment and procedures necessary for the collection of water samples for the purpose of this study; (3) the characterization of surface and groundwater chemistry used for direct and indirect sources of drinking water in the Summit Lake West Virginia prior to drilling, and establishing baseline water chemistry conditions.

Research conducted using temporal studies of unconventional drilling effects on water resources, especially through the use of stable isotopes, were identified as important knowledge gaps in the literature. This study initiates the start of a pre- versus post-drilling investigation of shallow groundwater quality using stable isotopes to provide the framework from which to evaluate potential changes from shale gas development near Summit Lake West Virginia. This study initiates research which will add to the body of knowledge surrounding impacts of unconventional shale gas development to water resources and will begin to fill knowledge gaps and therefore aid the management of water resources.

\section{2 - Limitations, Future Work, and Directions}

In order to characterize surface and groundwater quality in the Summit Lake recreational area, an understanding of their interactions and the boundary conditions of watersheds are necessary. A primary limitation of this study was the small sample size (spatial and temporal) resulting from a limited number of sampling locations. Errors associated with sampling 
techniques were not evaluated in this study and should be included in future sampling operations. Replication would increase the confidence associated with characterization, and would allow for further interpretation of water chemistry. Future study objectives for this region should incorporate and evaluate previously collected data by the Forest Service for public health inventories. This data could be used to further evaluate long term water quality trends for the area. Although benefits exist with continuing to sample current locations through time, consideration should be given to extending the spatial extent of the study as natural gas development is likely to increase across the Monongahela National Forest in areas where mineral rights are not federally owned. A benefit of this strategy is that it would allow for a broader regional understanding of drinking water resources. It is important to address large uncertainties such as the timing and location of future drilling operations. Because of the unpredictable nature of potential contamination events, a broader spatial component to this study may be more appropriate for capturing variability in these surface and groundwater systems. With methane known to exist in regional aquifers (Table 12), increasing the spatial extent of sampling using geochemistry and isotopes may provide a better understanding of the spatial variability and inherent complexity of these mountain systems. This could also help to elucidate possible trends in migration of methane, which have previously been linked to topography [Molofsky et al., 2011].

At a larger-scale, collaborative efforts should combine datasets with future ongoing studies in the area. This proposed data set, stratified by individual watersheds, could potentially be used to interpolate surface and subsurface hydro-chemical signatures across the region. Continuously updating this dataset with newly sampled wells and incorporating parameters that can ultimately affect water chemistry and include land cover, elevation, proximity to energy 
extraction areas, sewage treatment plants, etc. will be an important component of water resources monitoring.

Future studies should also consider seismic data to analyze local geology, such as natural fractures, that could connect deeper formations to shallower ones used for public and private drinking sources. Quantifying the extent of previous oil and gas development in the region and the possible abandoned wells is important for explaining and identifying potential contamination pathways. Longstanding and recently proposed gas operations in Monongahela National Forest can be seen in Figure 13. These locations provide a starting point for locating permitted wells and legacy infrastructure. Buffering these potential transport pathways from drilling activities should be considered an important strategy for mitigating potential impacts. Ground water modeling also could help explain potential issues in the case of a gas well failure. Identifying aquifer boundary conditions, transmissivity, and other important hydrogeologic properties will lead to additional insights for management of these aquifer sources.

Considerable attention and resources have been brought to shallow drinking water aquifers and subsurface contamination events. This has led to some baseline water chemistry testing throughout the mid-Atlantic region, but various levels of intensity and thoroughness exist in these evaluations. Focus on filling these gaps, through standardizing testing parameters and techniques should be a key objective in moving forward with sampling in shale gas development areas. However, equal importance should be placed on management of wastewater as well as the transport and treatment/ discharge of produced water. These factors represent large issues in extraction areas and have the potential to constitute significant water quality impacts. 
Results from this study add to sampling and characterization throughout the region as part of ongoing studies at West Virginia University [Mulder et al., 2012]. Methane concentrations, isotope analysis, and geochemical results presented here serve as a baseline of water chemistry prior to drilling and hydraulic fracturing, which will be used as a basis for comparison in future studies. Post-drilling samples will be collected depending on timing of the well completion. This research provides the foundation for investigating water quality issues related to the shale gas development surrounding Summit Lake, West Virginia. As we move forward with shale gas development in this area, we now have a reference point from which to assess changes in local water chemistry before, during, and after shale gas extraction. 


\section{Figures}

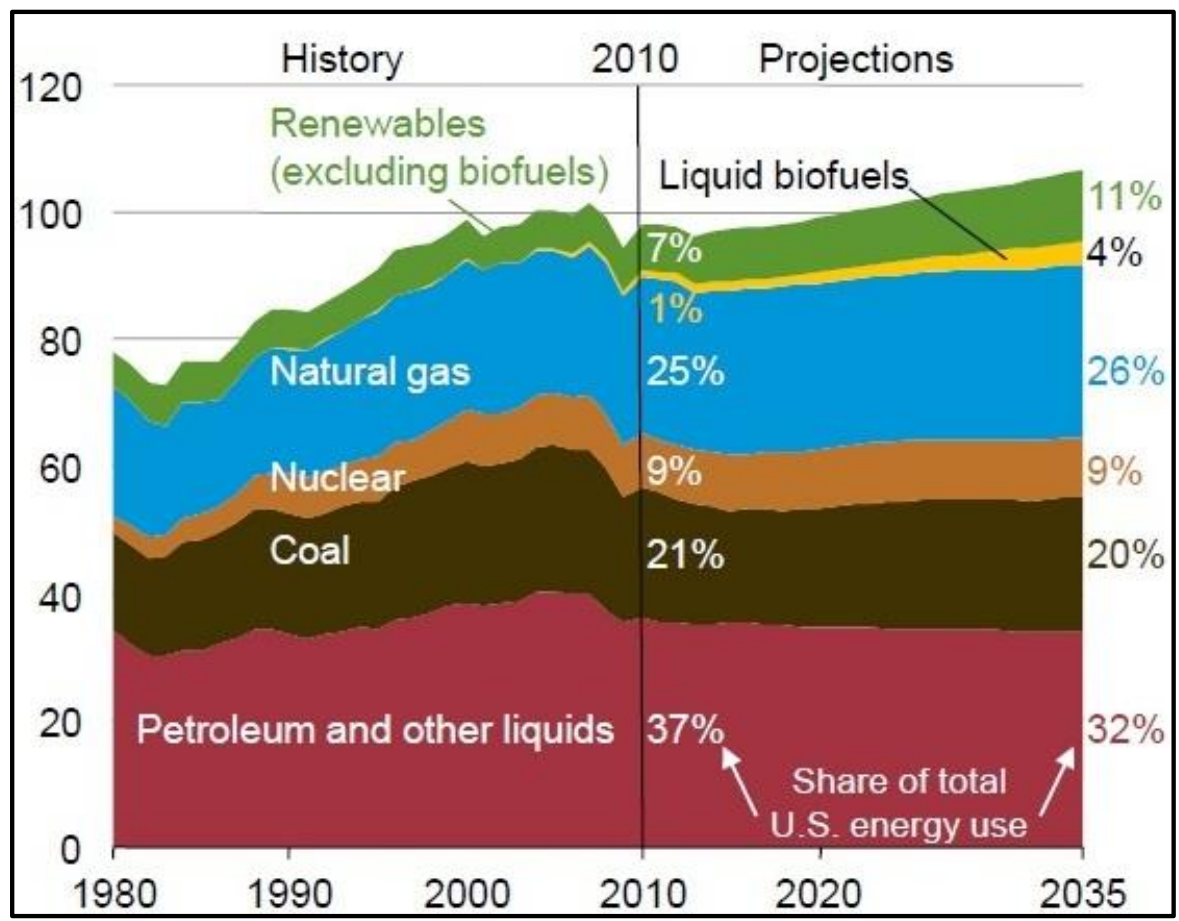

Figure 1: Primary energy use of the United States by fuel 1980-2035 [US EIA, 2012]

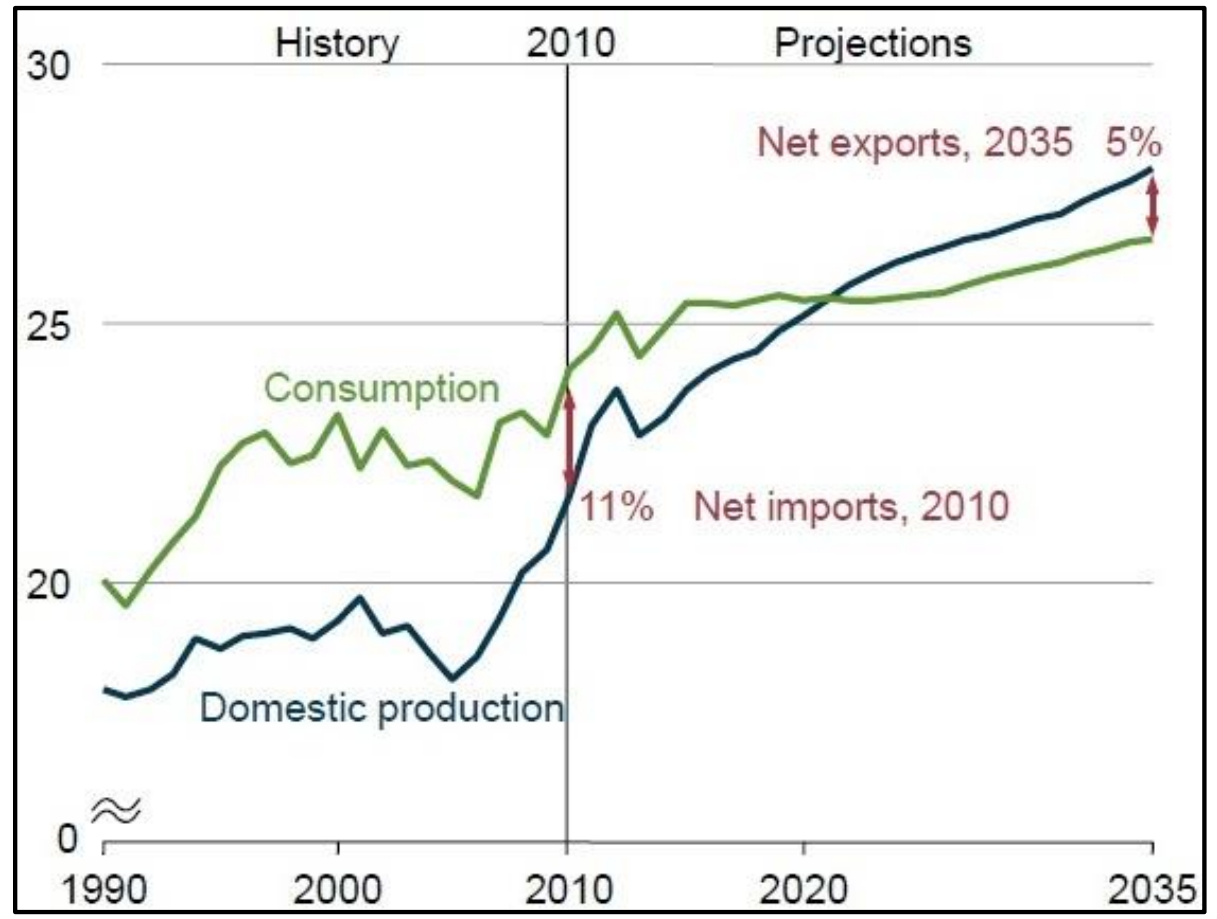

Figure 2: Total U.S. Natural Gas Consumption, Domestic Production, and Net Imports 19902035 [US EIA, 2012] 


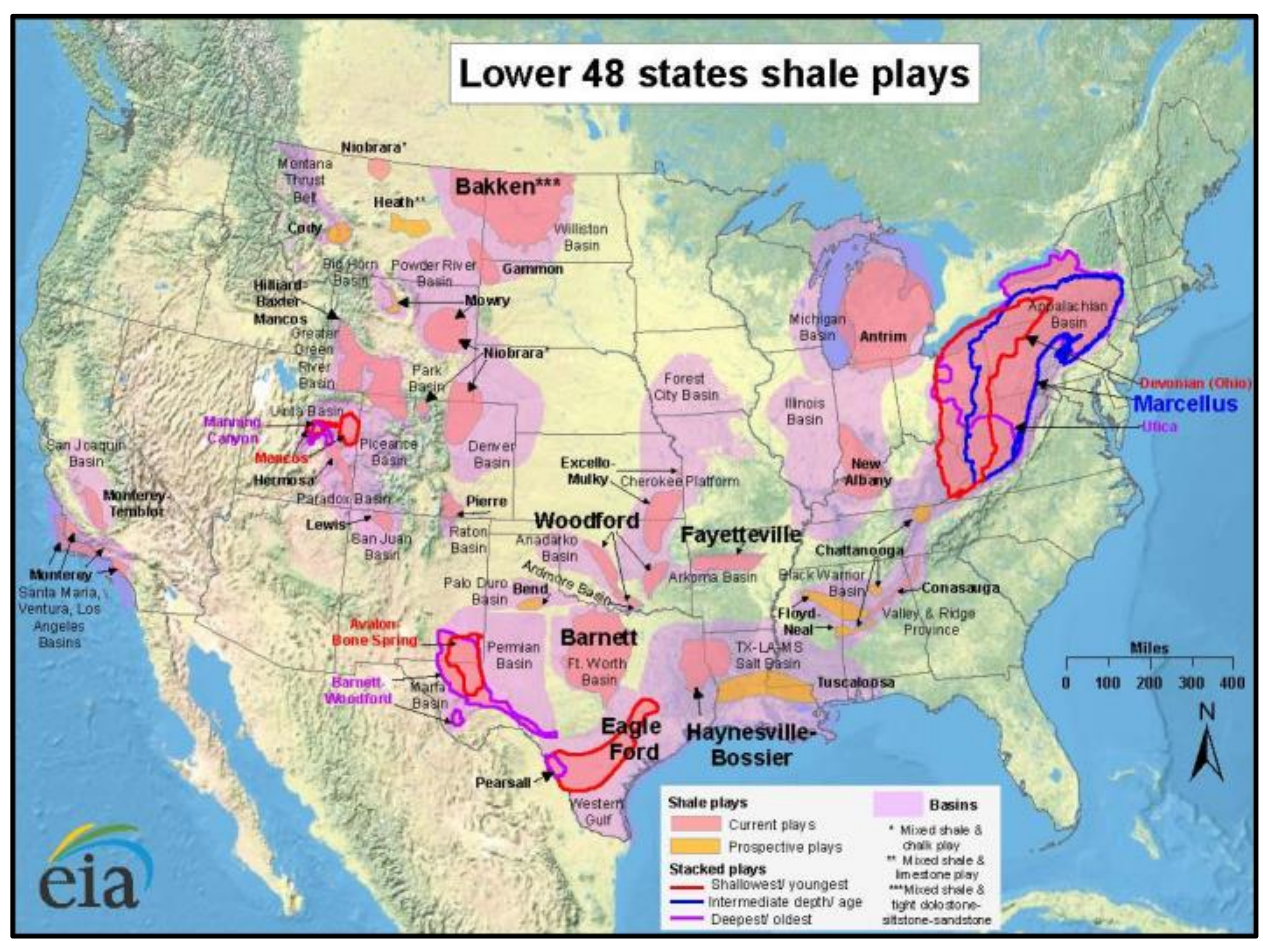

Figure 3: Map of current U.S. shale gas and shale oil plays [US EIA, 2011]

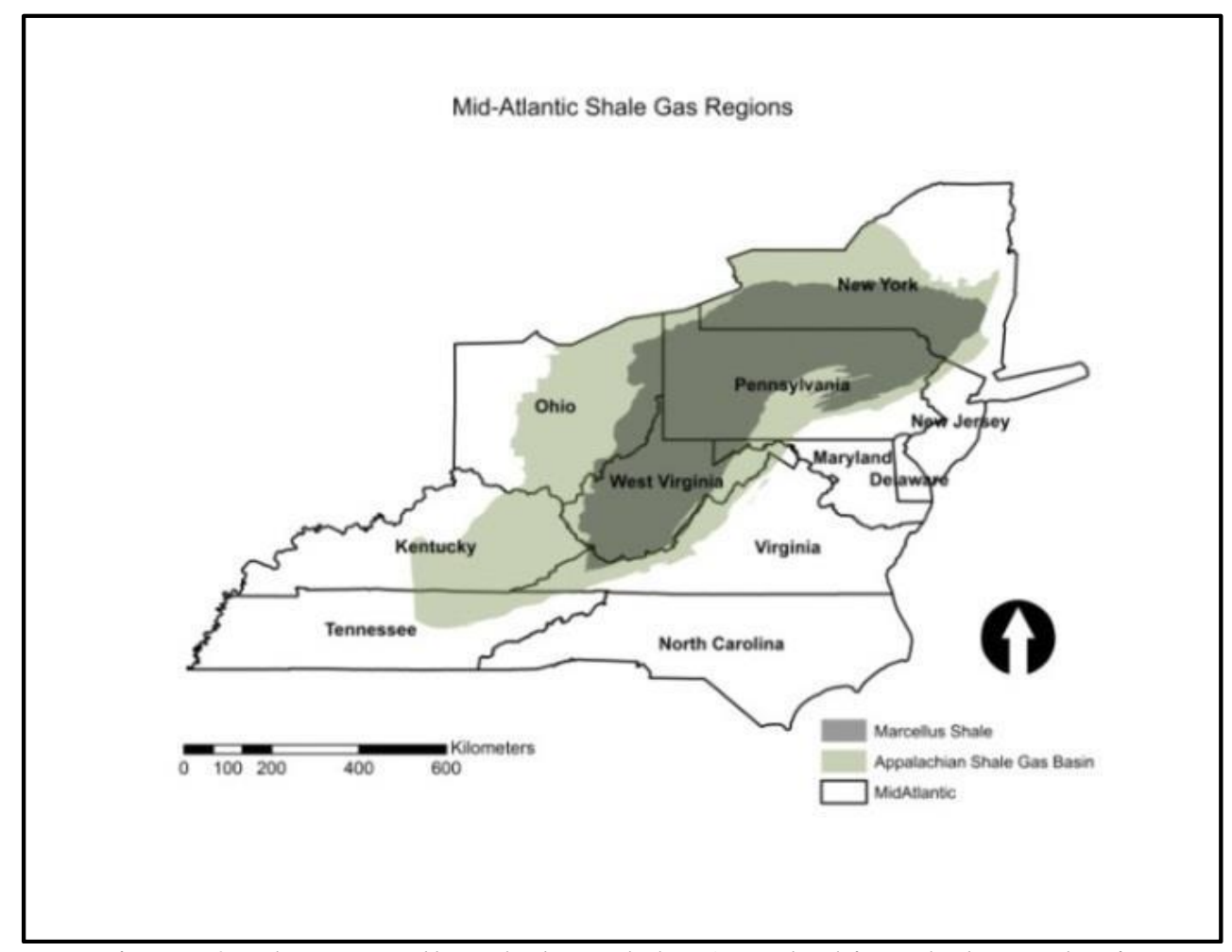

Figure 4: The Marcellus shale and the Appalachian shale gas basin 


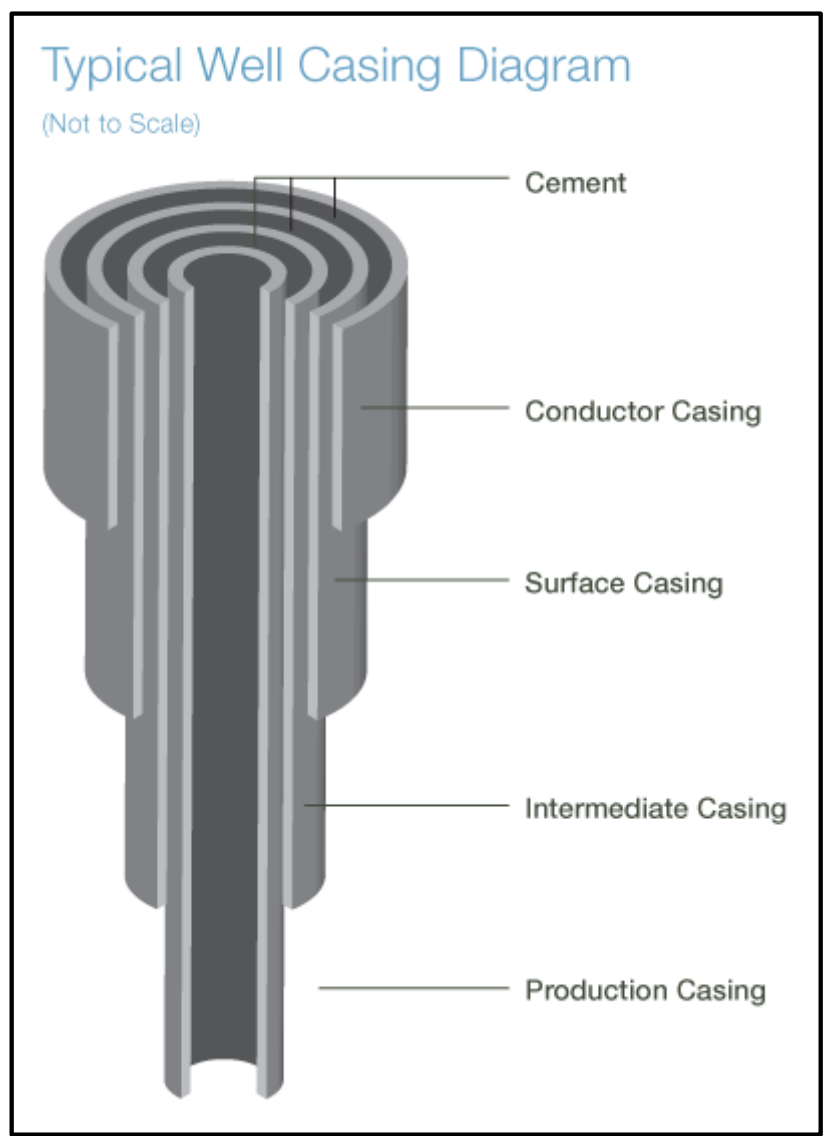

Figure 5: Typical well casing diagram [Encana, 2013] 


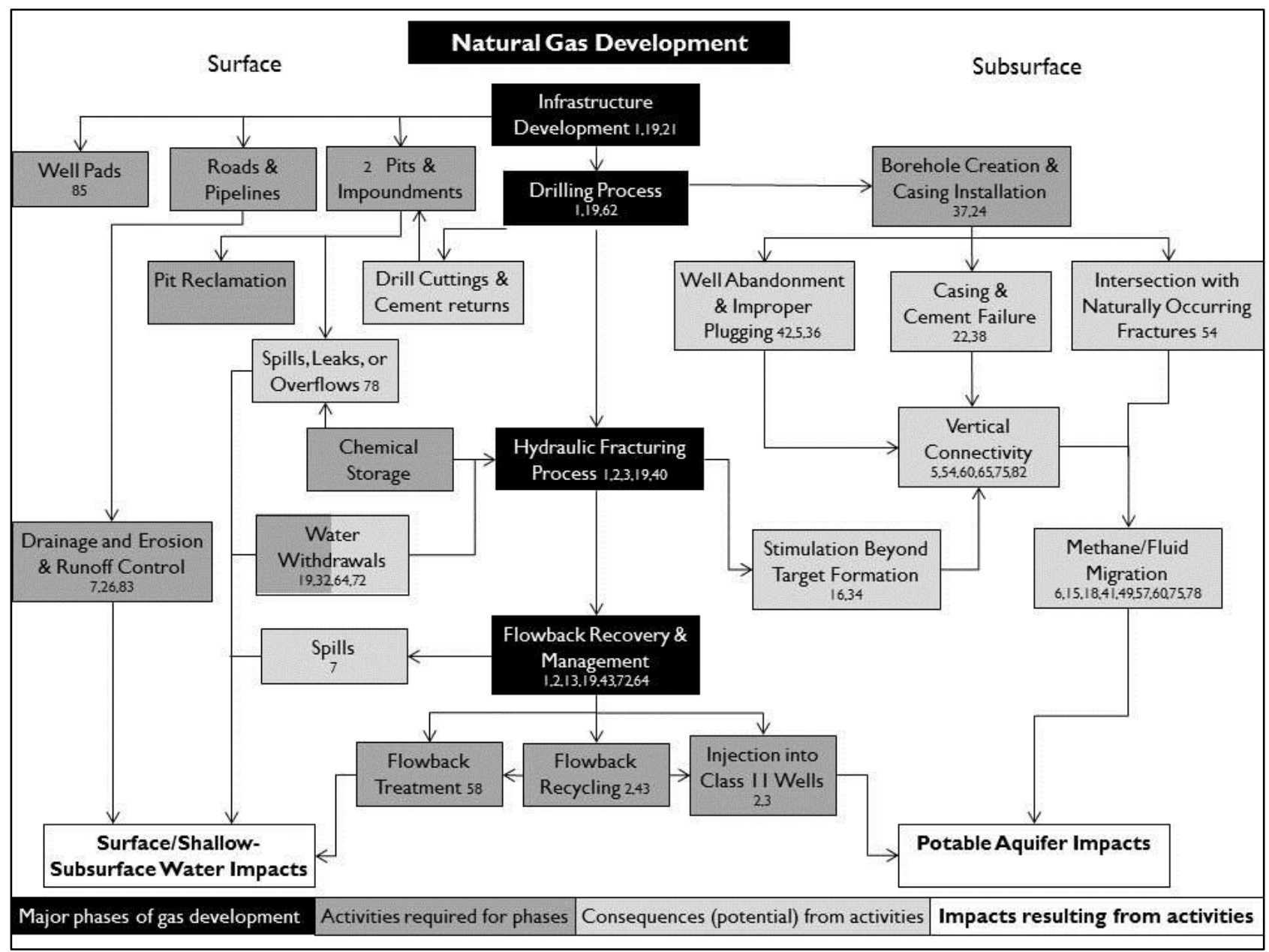

Figure 6: Conceptual model of potential unconventional gas development integrating surface and subsurface impacts on drinking water quality 


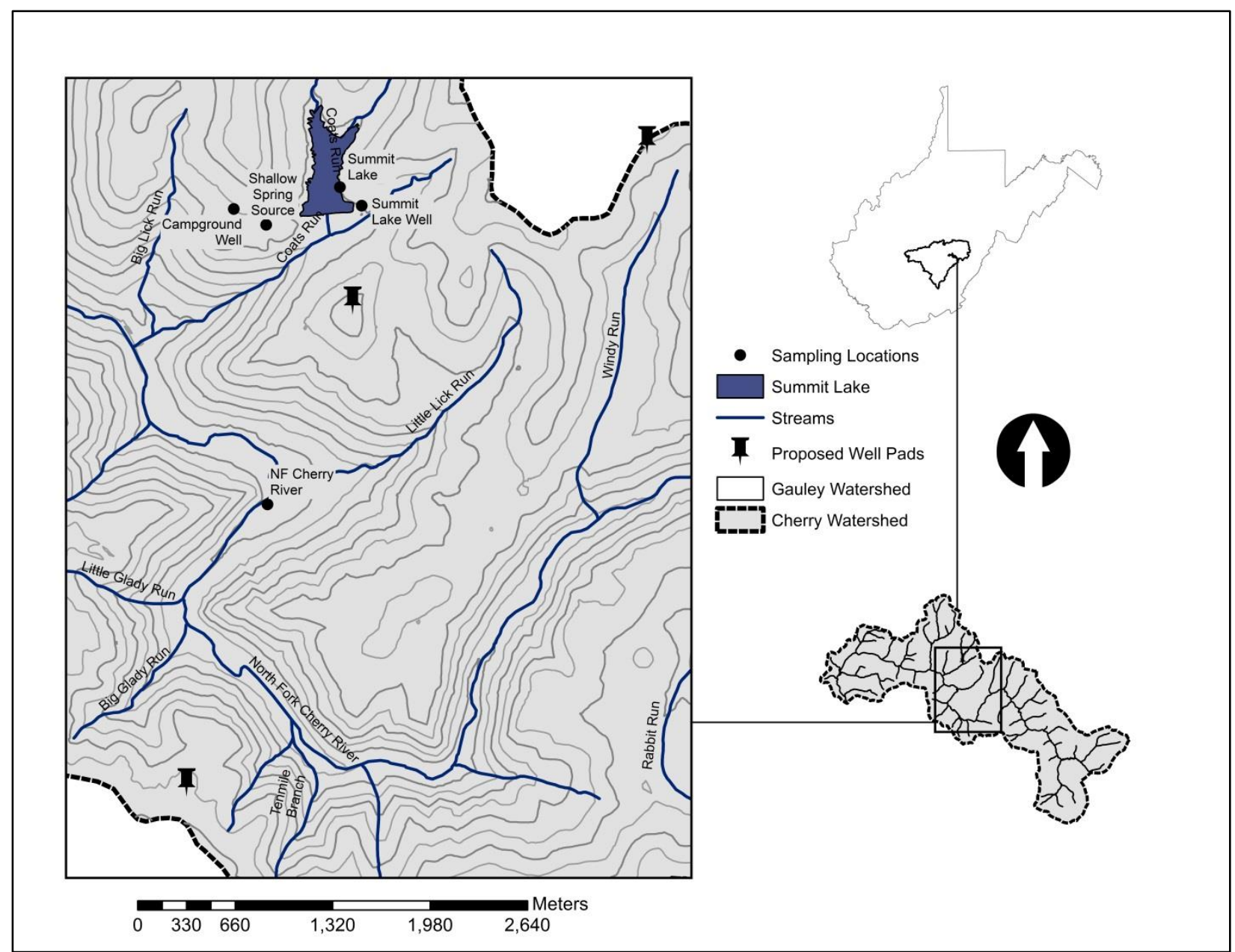

Figure 7: Proposed drilling and current sampling locations in the Cherry River Watershed on the Monongahela National Forest 


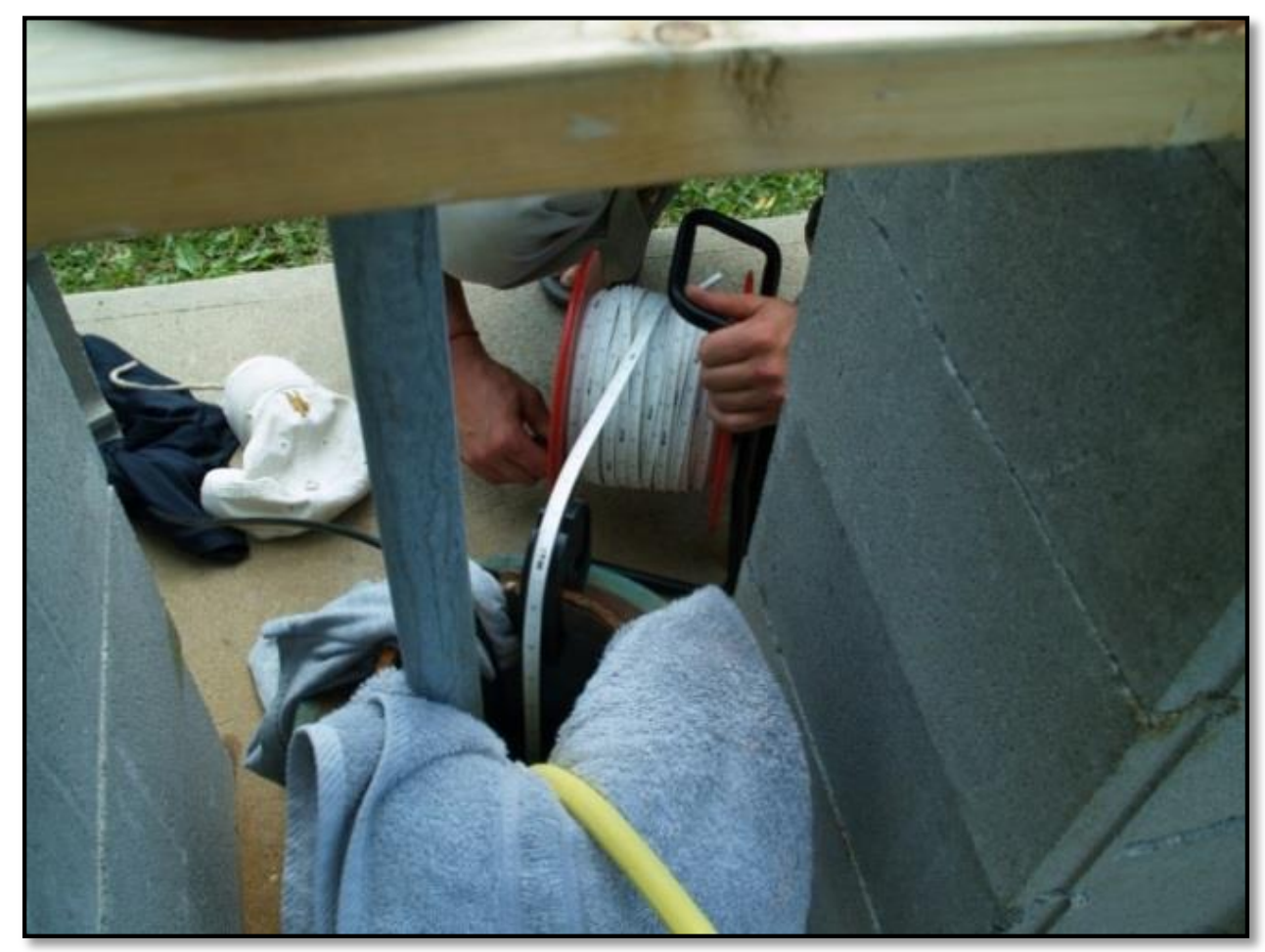

Figure 8: Accessing the Summit Lake well supported by a block and beam system

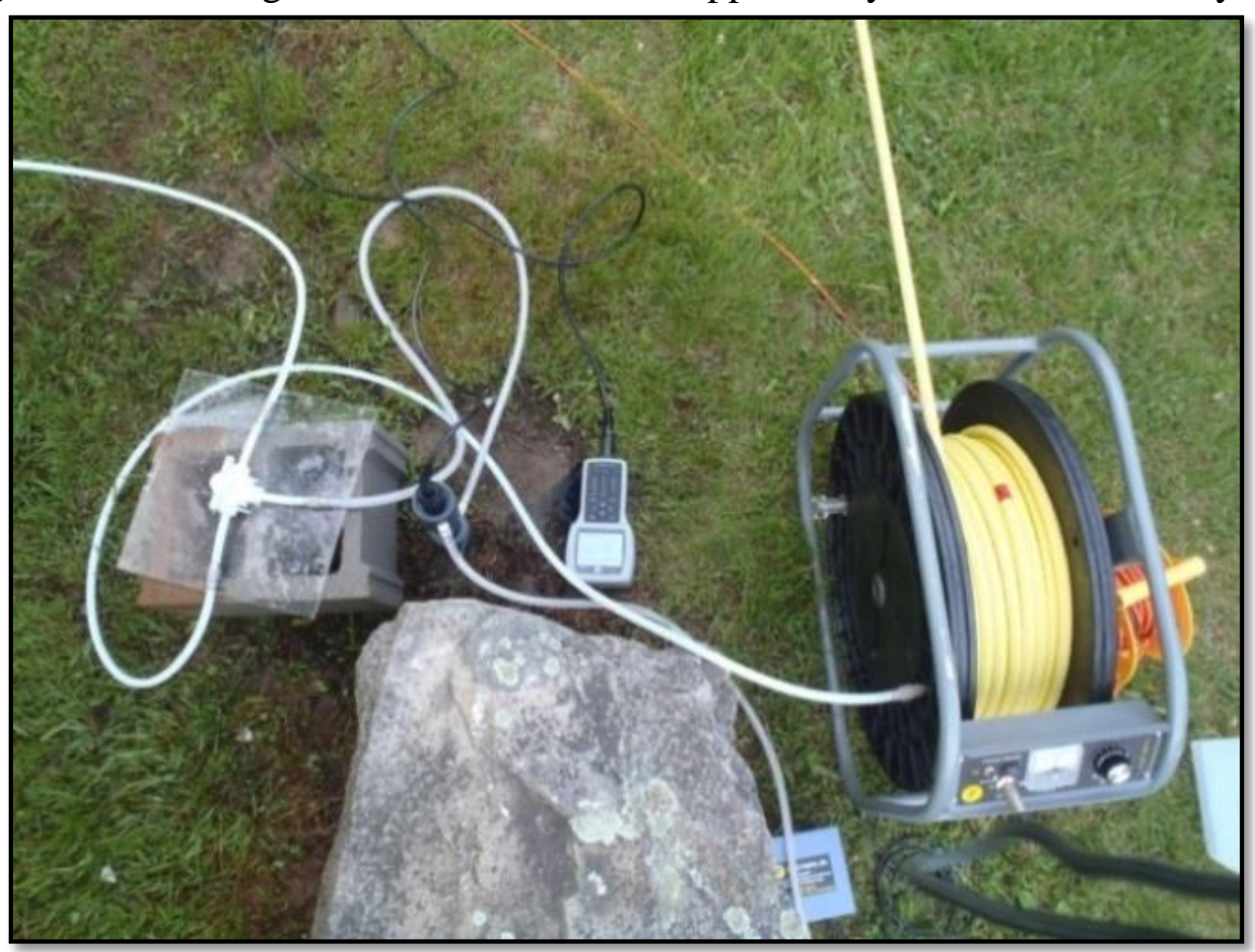

Figure 9: Foltz portable pumping system 


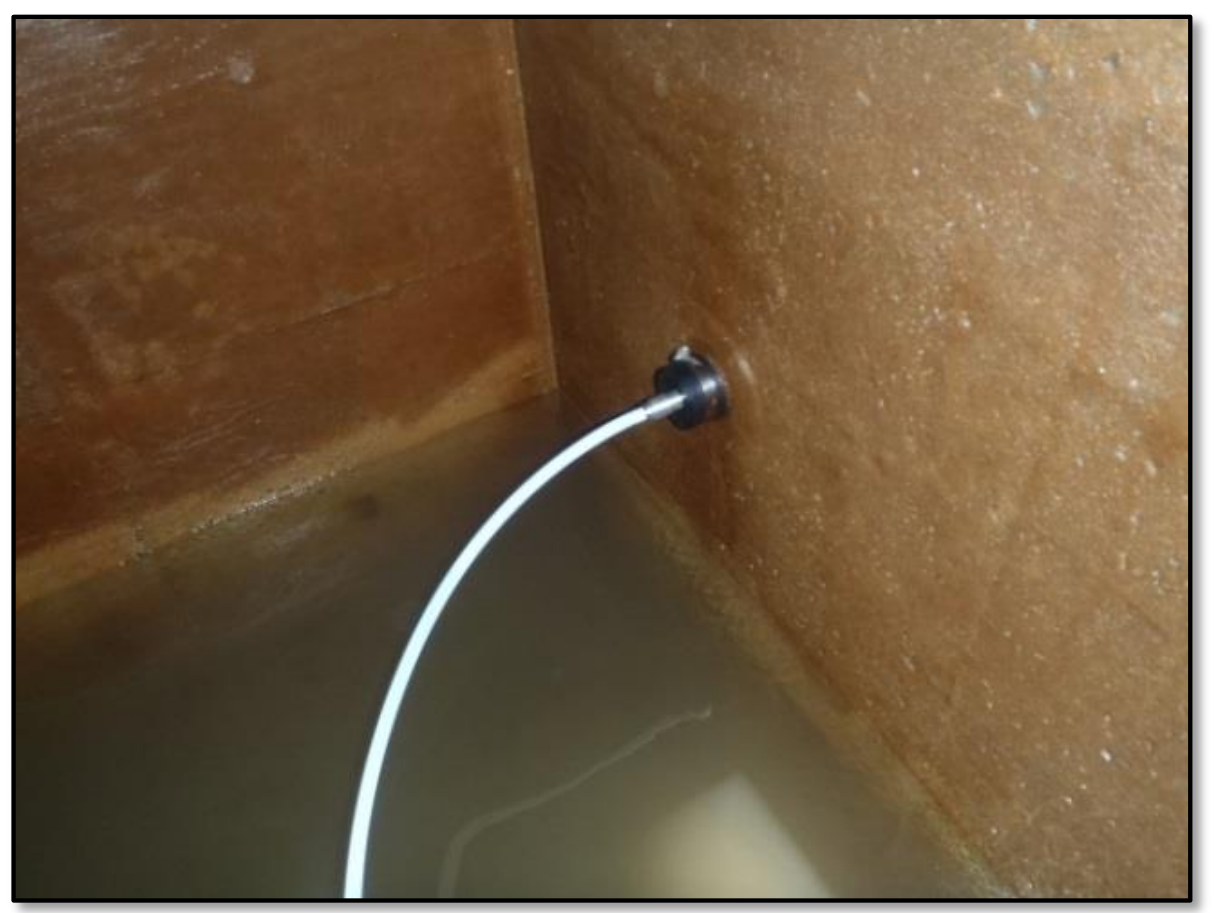

Figure 10: Quick connect coupler and pipe flange for sampling at the spring box 


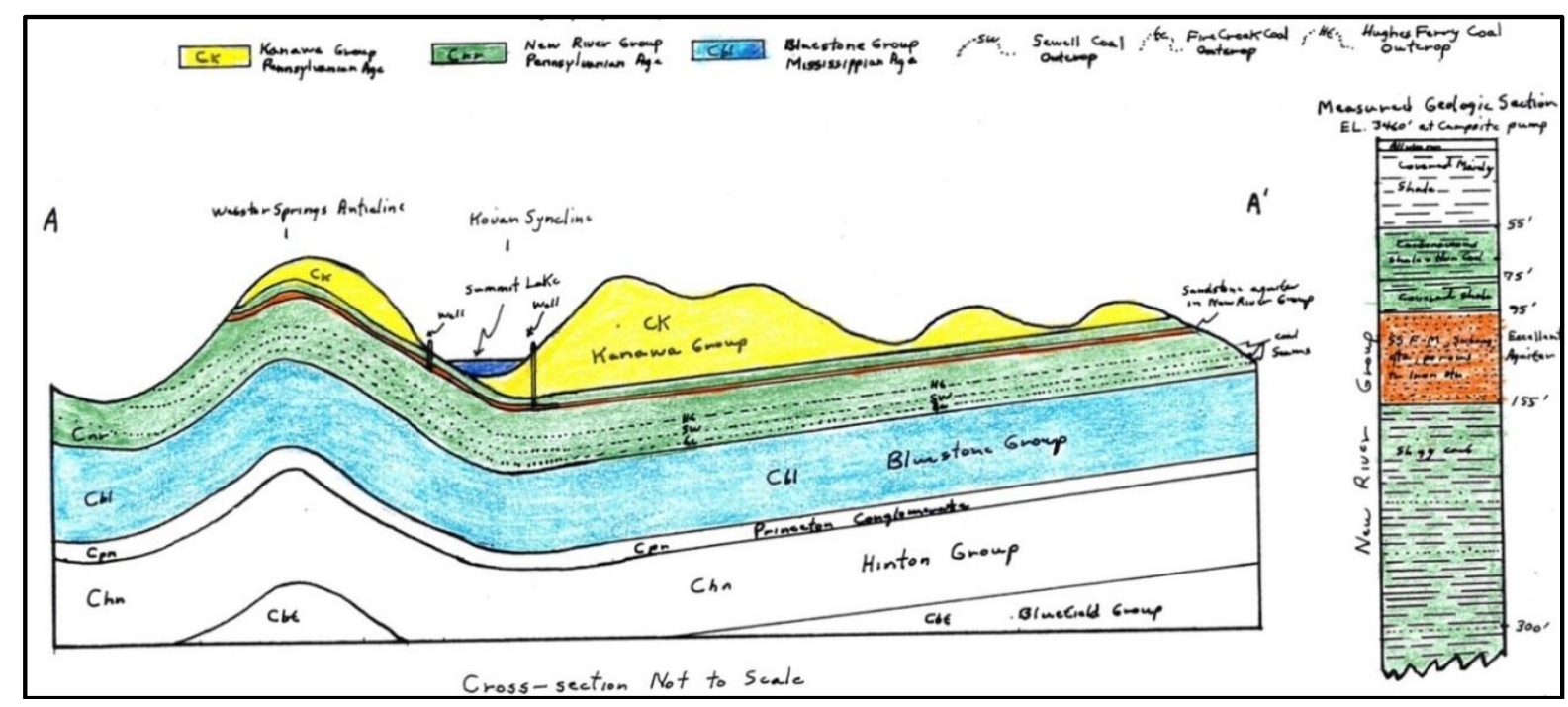

Figure 11: Geologic cross section of Summit Lake West Virginia [MacDonald, 1965]

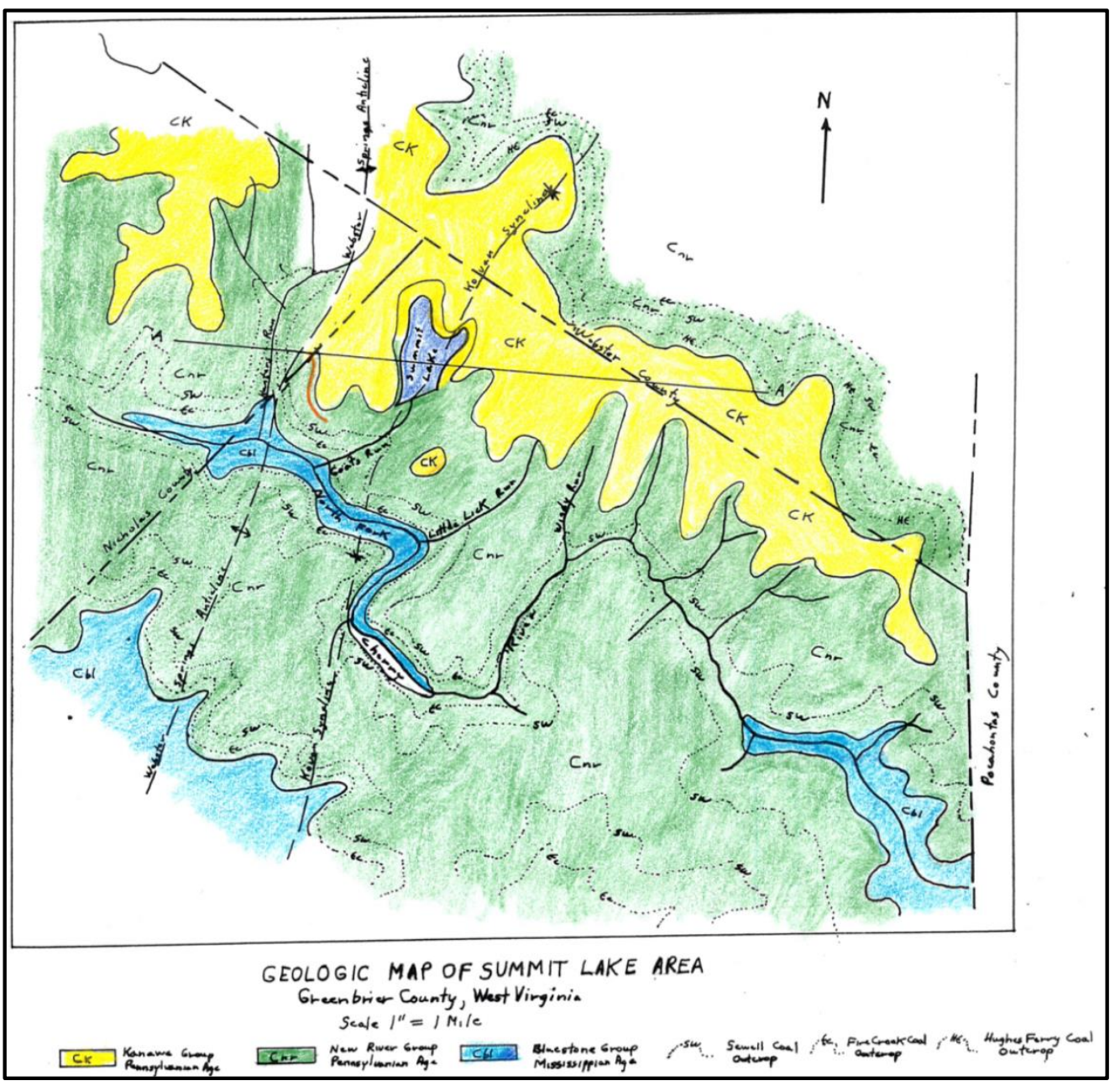

Figure 12: Geologic map of Summit Lake West Virginia [MacDonald, 1965] 


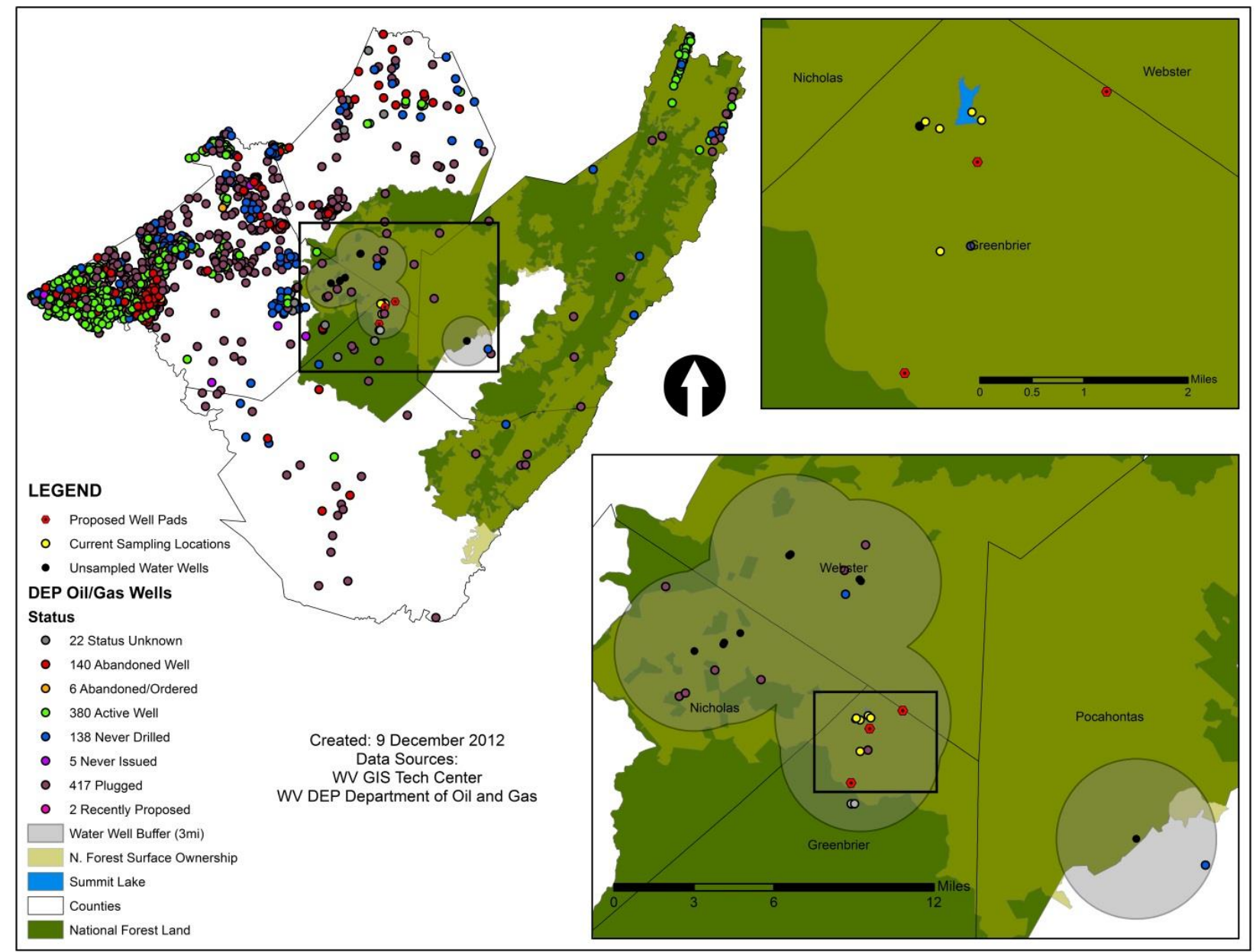

Figure 13: Longstanding and recently proposed gas operations in Monongahela National Forest 


\section{Tables}

Table 1: Conventional vs. Unconventional natural gas extraction methods

\begin{tabular}{lcc} 
& Conventional Extraction Methods & Unconventional Extraction Methods \\
\hline Well Type & Vertical & Horizontal \\
Hydraulic Fracturing & Often & Nearly Always \\
$*$ Water Use Per Well & $1.9-3.8$ Million Liters & $11.5-30.3$ Million Liters \\
$*$ Pad Size & $>0.4-1.2$ Hectares & $1.2-2.4$ Hectares \\
$*$ Pads Per sq. mi & 16 & 1 \\
\hline $\begin{array}{l}\text { Formation Examples in } \\
\text { the mid-Atlantic }\end{array}$ & Trenton/Black River & Marcellus \\
\hline$*$ Estimated, as values vary and are specific to site and formation [Arthur et al., 2010; DOE and NETL, 2009; PRI, 2012]
\end{tabular}

Table 2: Comparison of literature end members for determining sources of methane

\begin{tabular}{lc|c|c|c}
\multicolumn{1}{c}{ Author } & \multicolumn{2}{c|}{ Biogenic (approx.) } & \multicolumn{2}{c}{ Thermogenic (approx.) } \\
\cline { 2 - 5 } \multicolumn{1}{c}{$\% \delta^{13} \mathrm{C}_{\mathrm{CH} 4}$} & $\% \delta^{2} \mathrm{H}_{\mathrm{CH} 4}$ & $\% \delta^{13} \mathrm{C}_{\mathrm{CH} 4}$ & $\delta^{2} \mathrm{H}_{\mathrm{CH} 4}$ \\
\hline \hline Clark et al. [1997] & -40 to -90 & -150 to -300 & -35 to -50 & -150 to -185 \\
Whiticar [1999] & -45 to -80 & -140 to $<-450$ & -20 to -50 & $>-100$ to -340 \\
Osborn et al. [2011] & -64 to $<-80$ & -158 to $<-300$ & $>-20$ to -50 & $>-0$ to $<-300$ \\
Schoell [1980] & -64 to $<-90$ & -149 to $<-300$ & -20 to -56 & -125 to -275 \\
Ryder et al. [2003] & -65 to $<-80$ & -160 to $<-325$ & $>-20$ to -63 & -160 to $<-325$ \\
Molofsky et al. [2011] & -63 to $<-90$ & -200 to $<-325$ & $>-20$ to -64 & $>-100$ to -255 \\
\hline
\end{tabular}

Table adapted from [Mulder, 2012] 
Table 3: EPA Maximum Contaminant Levels (MCL) for radioactive elements / particles in drinking water

\begin{tabular}{lc}
\hline Radioactive element & MCL \\
\hline \hline Uranium & $30 \mu \mathrm{g} / \mathrm{L}$ \\
Radium & $5 \mathrm{pCi} / \mathrm{L}$ \\
Alpha particles & $15 \mathrm{pCi} / \mathrm{L}$ \\
Beta particles & 4 millirems / year \\
\hline
\end{tabular}

[USEPA, 2009; Palacios, 2012]

Table 4: Field parameters of sampling locations near Summit Lake West Virginia

\begin{tabular}{lccrrrrr}
\hline \multicolumn{1}{r}{ Site Name } & Aquifer Formation/Group & Geologic Age & Date & $\begin{array}{r}\text { Time } \\
\text { Temp }\left({ }^{\circ} \mathrm{C}\right)\end{array}$ & $\begin{array}{r}\text { pH } \\
(\mathrm{ft} .)\end{array}$ \\
\hline \hline USFS-SP & - & - & $6 / 19 / 2012$ & 1136 & 10.45 & 5 \\
USFS-CR & - & - & $6 / 20 / 2012$ & 1530 & 21.59 & 7.29 & - \\
USFS-SL & - & - & $6 / 19 / 2012$ & 1700 & 23.13 & 6.75 & - \\
USFS-9913048 & New River & Pennsylvanian & $6 / 20 / 2012$ & 1720 & 9.85 & 5.69 & 120 \\
USFS-9913010 & New River & Pennsylvanian & $6 / 21 / 2012$ & 2105 & 11.14 & 6.05 & 114 \\
\hline
\end{tabular}


Table 5: EPA Maximum Contaminant Levels (MCL) \& Secondary Standards for salts and pH in groundwater

\begin{tabular}{lcl}
\hline Constituent & MCL $(\mathbf{m g} / \mathbf{l})$ & \multicolumn{1}{c}{ Health Effects } \\
\hline \hline $\mathrm{pH}$ & $* 6.5-8.5$ & - \\
Chloride & $* 250$ & - \\
Sulfate & $* 250$ & \\
TDS & $* 500$ & \\
Bromate & 0.01 & Increased risk of cancer \\
Nitrate & 10 & $\begin{array}{l}\text { Serious complications in infants < six months; shortness of breath and blue-baby } \\
\text { syndrome }\end{array}$ \\
Selenium & 0.05 & Hair and fingernail loss; numbness in fingers or toes; circulatory problems \\
\hline
\end{tabular}

* EPA Secondary Standard [USEPA, 2009; Palacios, 2012] 
Table 6: EPA Maximum Contaminant Levels (MCL) \& Secondary Standards for metals in drinking water \& associated health effects

\begin{tabular}{|c|c|c|}
\hline Element & MCL (mg/l) & Health Effects \\
\hline Aluminum & $* 0.05-0.2$ & - \\
\hline Antimony & 0.006 & Increase in blood cholesterol; decrease in blood sugar \\
\hline Arsenic & 0.01 & Skin damage, circulatory system complication, increase cancer risk \\
\hline Barium & 2 & Increase in blood pressure \\
\hline Beryllium & 0.004 & Intestinal lesions \\
\hline Cadmium & 0.005 & Kidney damage \\
\hline Chromium & 0.1 & Allergic dermatitis \\
\hline Copper & 1 & - \\
\hline Iron & $* 0.3$ & - \\
\hline Lead & 0.015 & $\begin{array}{l}\text { Infants and Children: Physical and mental health; } \\
\text { Adults: Kidney problems; high blood pressure }\end{array}$ \\
\hline Manganese & $* 0.05$ & - \\
\hline Mercury & 0.002 & Kidney damage \\
\hline Selenium & 0.05 & Hair and fingernail loss; numbness in fingers or toes; circulatory problems \\
\hline Silver & $* 0.10$ & - \\
\hline
\end{tabular}

* EPA Secondary Standard [USEPA, 2009; Palacios, 2012] 
Table 7: ICP-MS analysis, trace metal concentrations of sampling locations in Summit Lake West Virginia.

\begin{tabular}{lccccccccccccc}
\hline Constituent & $\begin{array}{c}\mathrm{Ag} \\
\mathrm{ppb}\end{array}$ & $\begin{array}{c}\mathrm{Al} \\
\mathrm{ppb}\end{array}$ & $\begin{array}{c}\mathrm{As} \\
\mathrm{ppb}\end{array}$ & $\begin{array}{c}\mathrm{Au} \\
\mathrm{ppb}\end{array}$ & $\begin{array}{c}\mathrm{Ba} \\
\mathrm{ppb}\end{array}$ & $\begin{array}{c}\mathrm{Be} \\
\mathrm{ppb}\end{array}$ & $\begin{array}{c}\mathrm{Bi} \\
\mathrm{ppb}\end{array}$ & $\begin{array}{c}\mathrm{Ca} \\
\mathrm{ppb}\end{array}$ & $\begin{array}{c}\mathrm{Cd} \\
\mathrm{ppb}\end{array}$ & $\begin{array}{c}\mathrm{Ce} \\
\mathrm{ppb}\end{array}$ & $\begin{array}{c}\mathrm{Co} \\
\mathrm{ppb}\end{array}$ & $\begin{array}{c}\mathrm{Cr} \\
\mathrm{ppb}\end{array}$ \\
\hline \hline USFS-SP & 0.017 & $<5$ & 0.08 & $<0.004$ & 59.28 & $<0.01$ & $<0.002$ & 3859 & 0.01 & 0.011 & 0.067 & 0.15 \\
USFS-CR & 0.017 & 30 & 0.09 & $<0.004$ & 122.84 & 0.02 & $<0.002$ & 7581 & 0.01 & 0.023 & 0.031 & 0.11 \\
USFS-SL & 0.007 & 36 & 0.32 & $<0.004$ & 87.22 & 0.02 & 0.002 & 4163 & 0.01 & 0.04 & 0.09 & 0.15 & 0.17 \\
USFS-9913048 & 0.018 & $<5$ & $<0.03$ & $<0.004$ & 81.42 & 0.01 & $<0.002$ & 7075 & 0.17 & 0.005 & 0.025 & 0.14 \\
USFS-9913010 & 0.014 & $<5$ & 0.32 & $<0.004$ & 321.15 & 0.03 & 0.011 & 11081 & 0.01 & 0.019 & 0.049 & 0.19 \\
\hline Detection Limit & 0.005 & 5 & 0.03 & 0.004 & 0.02 & 0.01 & 0.002 & 25 & 0.01 & 0.002 & 0.005 & 0.02 \\
\hline
\end{tabular}

Table 8: ICP-MS analysis, trace metal concentrations of sampling locations in Summit Lake West Virginia.

\begin{tabular}{lcccccccccccc}
\hline Constituent & $\begin{array}{c}\mathrm{Cs} \\
\mathrm{ppb}\end{array}$ & $\begin{array}{c}\mathrm{Cu} \\
\mathrm{ppb}\end{array}$ & $\begin{array}{c}\mathrm{Dy} \\
\mathrm{ppb}\end{array}$ & $\begin{array}{c}\mathrm{Er} \\
\mathrm{ppb}\end{array}$ & $\begin{array}{c}\mathrm{Eu} \\
\mathrm{ppb}\end{array}$ & $\begin{array}{c}\mathrm{Fe} \\
\mathrm{ppb}\end{array}$ & $\begin{array}{c}\mathrm{Ga} \\
\mathrm{ppb}\end{array}$ & $\begin{array}{c}\mathrm{Gd} \\
\mathrm{ppb}\end{array}$ & $\begin{array}{c}\mathrm{Hf} \\
\mathrm{ppb}\end{array}$ & $\begin{array}{c}\mathrm{Ho} \\
\mathrm{ppb}\end{array}$ & $\begin{array}{c}\mathrm{La} \\
\mathrm{ppb}\end{array}$ & $\begin{array}{c}\mathrm{Li} \\
\mathrm{ppb}\end{array}$ \\
\hline \hline USFS-SP & 0.0007 & $<0.2$ & 0.003 & 0.001 & $<0.0004$ & $<3$ & 0.002 & 0.003 & $<0.004$ & 0.0008 & 0.003 & 1.25 \\
USFS-CR & 0.0009 & 0.3 & 0.007 & 0.004 & $<0.0004$ & 6 & 0.003 & 0.007 & $<0.004$ & 0.0014 & 0.026 & 0.37 \\
USFS-SL & 0.0011 & 0.3 & 0.005 & 0.003 & 0.0011 & 373 & 0.01 & 0.006 & $<0.004$ & 0.001 & 0.023 & 0.35 \\
USFS-9913048 & 0.0019 & $<0.2$ & 0.001 & 0.001 & $<0.0004$ & 4 & 0.002 & 0.001 & $<0.004$ & 0.0001 & 0.002 & 4.3 \\
USFS-9913010 & 0.0067 & 3 & 0.026 & 0.02 & $<0.0004$ & $>1700$ & 0.05 & 0.032 & 0.004 & 0.0054 & 0.006 & 4.6 \\
\hline Detection Limit & 0.0005 & 0.2 & 0.001 & 0.001 & 0.0004 & 3 & 0.002 & 0.001 & 0.004 & 0.0001 & 0.001 & 0.01 \\
\hline
\end{tabular}


Table 9: ICP-MS analysis, trace metal concentrations of sampling locations in Summit Lake West Virginia.

\begin{tabular}{lccccccccccccc}
\hline Constituent & $\begin{array}{c}\mathrm{Lu} \\
\mathrm{ppb}\end{array}$ & $\begin{array}{c}\mathrm{Mg} \\
\mathrm{ppb}\end{array}$ & $\begin{array}{c}\mathrm{Mn} \\
\mathrm{ppb}\end{array}$ & $\begin{array}{c}\mathrm{Mo} \\
\mathrm{ppb}\end{array}$ & $\begin{array}{c}\mathrm{Nb} \\
\mathrm{ppb}\end{array}$ & $\begin{array}{c}\mathrm{Nd} \\
\mathrm{ppb}\end{array}$ & $\begin{array}{c}\mathrm{Ni} \\
\mathrm{ppb}\end{array}$ & $\begin{array}{c}\mathrm{Pb} \\
\mathrm{ppb}\end{array}$ & $\begin{array}{c}\mathrm{Pr} \\
\mathrm{ppb}\end{array}$ & $\begin{array}{c}\mathrm{Rb} \\
\mathrm{ppb}\end{array}$ & $\begin{array}{c}\mathrm{Sb} \\
\mathrm{ppb}\end{array}$ & $\begin{array}{c}\mathrm{Sc} \\
\mathrm{ppb}\end{array}$ \\
\hline \hline USFS-SP & 0.0003 & 1345 & $<3$ & 0.01 & 0.001 & 0.01 & 1.2 & $<0.05$ & 0.0017 & 0.183 & 0.01 & $<0.1$ \\
USFS-CR & 0.001 & 1291 & $<3$ & 0.04 & $<0.001$ & 0.035 & 0.4 & $<0.05$ & 0.0074 & 0.496 & 0.02 & $<0.1$ \\
USFS-SL & 0.0004 & 501 & 56 & 0.03 & 0.002 & 0.025 & 0.7 & 0.09 & 0.0076 & 0.126 & 0.03 & 0.1 & 26 \\
USFS-9913048 & 0.0001 & $>4000$ & $<3$ & 0.01 & $<0.001$ & $<0.003$ & 2 & $<0.05$ & $<0.0004$ & 0.398 & 0.03 & $<0.1$ \\
USFS-9913010 & 0.0028 & $>4000$ & $>150$ & 0.06 & 0.001 & 0.029 & 0.2 & 0.67 & 0.0035 & 2.452 & 0.05 & 0.3 \\
\hline Detection Limit & 0.0001 & 1 & 3 & 0.01 & 0.001 & 0.003 & 0.1 & 0.05 & 0.0004 & 0.005 & 0.01 & 0.1 \\
\hline
\end{tabular}

Table 10: ICP-MS analysis, trace metal concentrations of sampling locations in Summit Lake West Virginia.

\begin{tabular}{lccccccccccccc}
\hline Constituent & $\begin{array}{c}\mathrm{Se} \\
\mathrm{ppb}\end{array}$ & $\begin{array}{c}\mathrm{Sm} \\
\mathrm{ppb}\end{array}$ & $\begin{array}{c}\mathrm{Sn} \\
\mathrm{ppb}\end{array}$ & $\begin{array}{c}\mathrm{Sr} \\
\mathrm{ppb}\end{array}$ & $\begin{array}{c}\mathrm{Ta} \\
\mathrm{ppb}\end{array}$ & $\begin{array}{c}\mathrm{Tb} \\
\mathrm{ppb}\end{array}$ & $\begin{array}{c}\mathrm{Th} \\
\mathrm{ppb}\end{array}$ & $\begin{array}{c}\mathrm{Ti} \\
\mathrm{ppb}\end{array}$ & $\begin{array}{c}\mathrm{Tl} \\
\mathrm{ppb}\end{array}$ & $\begin{array}{c}\mathrm{Tm} \\
\mathrm{ppb}\end{array}$ & $\begin{array}{c}\mathrm{U} \\
\mathrm{ppb}\end{array}$ & $\begin{array}{c}\mathrm{V} \\
\mathrm{ppb}\end{array}$ \\
\hline \hline USFS-SP & $<0.2$ & 0.005 & $<0.01$ & 10.2 & $<0.0003$ & 0.0006 & $<0.001$ & 0.2 & 0.001 & 0.0004 & 0.0053 & 0.049 \\
USFS-CR & $<0.2$ & 0.008 & $<0.01$ & 31.5 & $<0.0003$ & 0.0012 & 0.002 & 0.3 & 0.001 & 0.0008 & 0.0054 & 0.082 \\
USFS-SL & $<0.2$ & 0.007 & $<0.01$ & 14.3 & $<0.0003$ & 0.0013 & 0.003 & 0.7 & 0.001 & 0.0004 & 0.0067 & 0.122 \\
USFS-9913048 & $<0.2$ & 0.002 & 0.02 & 21.4 & $<0.0003$ & 0.0001 & $<0.001$ & $<0.1$ & 0.001 & 0.0002 & 0.0019 & 0.013 \\
USFS-9913010 & $<0.2$ & 0.019 & 0.07 & 127.1 & $<0.0003$ & 0.0043 & 0.004 & 0.9 & 0.001 & 0.0025 & 0.0011 & 0.177 \\
\hline Detection Limit & 0.2 & 0.001 & 0.01 & 0.1 & 0.0003 & 0.0001 & 0.001 & 0.1 & 0.001 & 0.0001 & 0.0002 & 0.003 \\
\hline
\end{tabular}


Table 11: ICP-MS analysis, trace metal concentrations and Alkalinity of sampling locations in Summit Lake West Virginia.

\begin{tabular}{lcccccc}
\hline Constituent & $\mathrm{W}$ & $\mathrm{Y}$ & $\mathrm{Yb}$ & $\mathrm{Zn}$ & $\mathrm{Zr}$ & Alkalinity CaCO $_{3}$ \\
\hline \hline USFS-SP & $\mathrm{ppb}$ & $\mathrm{Ppb}$ & $\mathrm{ppb}$ & $\mathrm{ppb}$ & $\mathrm{ppb}$ & $8.1 \mathrm{mg} / \mathrm{L}$ \\
USFS-CR & $<0.01$ & 0.0158 & 0.002 & 43 & $<0.1$ & $15.0 \mathrm{mg} / \mathrm{L}$ \\
USFS-SL & $<0.01$ & 0.052 & 0.003 & 42 & $<0.1$ & $8.1 \mathrm{mg} / \mathrm{L}$ \\
USFS-9913048 & $<0.01$ & 0.0399 & 0.003 & 46 & $<0.1$ & $40.0 \mathrm{mg} / \mathrm{L}$ \\
USFS-9913010 & $<0.01$ & 0.0053 & $<0.001$ & $>1500$ & $<0.1$ & $70.0 \mathrm{mg} / \mathrm{L}$ \\
\hline Detection Limit & 0.03 & 0.183 & 0.015 & $>1500$ & 0.2 & - \\
\hline
\end{tabular}

Table 12: Isotopic signatures of sampling locations in Summit Lake West Virginia. All units in \%o less otherwise noted.

*-not enough analyte present for analysis

\begin{tabular}{|c|c|c|c|c|c|c|c|c|}
\hline & $\mathrm{CH}_{4}(\mathrm{mg} / \mathrm{L})$ & $\delta^{13} \mathrm{C}_{\mathrm{CH} 4}$ & $\delta^{2} \mathrm{H}_{\mathrm{CH} 4}$ & $\delta^{13} \mathrm{C}_{\mathrm{DIC}}$ & $\delta^{2} \mathrm{H}_{\mathrm{H} 20}$ & $\delta^{18} \mathrm{O}_{\mathrm{H} 20}$ & $\begin{array}{c}{ }^{228} \mathrm{Ra} \\
(\mathrm{pCi} / \mathrm{L})\end{array}$ & $\begin{array}{c}\text { Total Alpha } \\
\mathrm{Ra} /{ }^{226} \mathrm{Ra}(\mathrm{pCi} / \mathrm{L})\end{array}$ \\
\hline$\overline{\text { USFS-SP }}$ & - & - & - & -16.623 & -65.635 & -10.737 & - & - \\
\hline USFS-SL & - & - & - & -6.555 & -53.511 & -8.524 & 0.00739 & 0.00444 \\
\hline USFS-CR & - & - & - & -6.865 & -54.908 & -8.451 & - & - \\
\hline USFS-9913048 & $<0.00006$ & $*$ & $*$ & -14.233 & -65.305 & -10.537 & 1.08 & 0.00203 \\
\hline USFS-9913010 & 1.1 & -57.46 & -175.0 & -13.214 & -61.857 & -9.874 & 0.03 & 0.0193 \\
\hline
\end{tabular}


Table 13: Field hydrochemistry of sampling locations (Anions) in Summit Lake West Virginia.

\begin{tabular}{|c|c|c|c|c|c|c|c|c|}
\hline Constituent (ppm) & $\begin{array}{c}\text { Fluoride } \\
\left(\mathrm{F}^{-}\right) \\
\end{array}$ & $\begin{array}{c}\text { Chloride } \\
\left(\mathrm{Cl}^{-}\right)\end{array}$ & $\begin{array}{l}\text { Nitrite } \\
\left(\mathrm{NO}_{2}^{-}\right)\end{array}$ & $\begin{array}{c}\text { Bromide } \\
\left(\mathrm{Br}^{-}\right)\end{array}$ & $\begin{array}{l}\text { Nitrate } \\
\left(\mathrm{NO}_{3}{ }^{-}\right)\end{array}$ & $\begin{array}{c}\text { Phosphate } \\
\left(\mathrm{PO}_{4}^{3-}\right)\end{array}$ & $\begin{array}{l}\text { Sulfate } \\
\left(\mathrm{SO}_{4}^{2-}\right)\end{array}$ & $\mathrm{NO}_{2}+\mathrm{NO}_{3}$ \\
\hline USFS-SP & 0.04 & 0.62 & ND & ND & 1.20 & ND & 4.91 & ND \\
\hline USFS-CR & 0.07 & 3.51 & ND & ND & 1.24 & ND & 5.95 & ND \\
\hline USFS-SL & 0.05 & 0.77 & ND & ND & 0.22 & ND & 3.15 & ND \\
\hline USFS-9913048 & 0.31 & 0.73 & ND & ND & 0.26 & ND & 2.54 & ND \\
\hline USFS-9913010 & 0.19 & 1.71 & ND & ND & 0.58 & ND & 0.56 & ND \\
\hline Detection Limit & 0.01 & 0.04 & 0.03 & 0.05 & 0.03 & 0.05 & 0.05 & 0.02 \\
\hline
\end{tabular}




\section{References}

(1) ALL Consulting (2010), Projecting the Economic Impact of Marcellus Shale Gas Development in West Virginia: A Preliminary Analysis Using Publicly Available Data, All Consulting, Tulsa, OK. Report.

(2) American Petreloum Institute (2010), Water Management associated with hydraulic fracturing, 40 pp, American Petroleum Institute, Washington, DC. Report.

(3) Arthur, J. D., B. Bohm, and M. Layne (2008), Hydraulic Fracturing Considerations For Natural Gas Wells of the Marcellus Shale, The Ground Water Protection Council 2008 Annual Forum, Cincinnati, Ohio, (21-24 SEP 2008).

(4) Arthur, J. D., M. Uretsky, and P. Wilson (2010), Water Resources and Use for Hydraulic Fracturing in the Marcellus Shale Region, All Consulting, Tulsa, OK.

(5) Avci, C. B. (1994), Evaluation of flow leakage through abandoned wells and boreholes, Water Resources Research, 30(9), 2565-2578.

(6) Barker, J., and P. Fritz (1981), The occurrence and origin of methane in some groundwater flow systems, Canadian Journal of Earth Sciences, 18(12), 1802-1816.

(7) Bishop, R. (2011), Chemical and Biological Risk Assessment for Natural Gas Extraction in New York, Oneonta, NY: State University of New York College at Oneonta; Cooperstown, NY: Sustainable Otsego (28 Mar 2011).

(8) Blauvelt, S. C. (2010), The Pennsylvania Marcellus Shale Natural Gas Play Past-Present \& Future, paper presented at The Pennsylvania Emergency Management Agency Annual Conference, Lancaster Host Resort and Conference Center, September 15. 
(9) Boyer, E., B. Swistock, J. Clark, M. Madden, and D. Rizzo (2012), The Impact of Marcellus Gas Drilling on Rural Drinking Water Supplies, Report for The Center for Rural Pennsylvania, Pennsylvania State University.

(10) Brady, N. C., and R. R. Weil (1996), The nature and properties of soils, Prentice-Hall Inc.

(11) Brinck, E. L., and C. D. Frost (2007), Detecting infiltration and impacts of introduced water using strontium isotopes, Groundwater, 45(5), 554-568.

(12) Chambers, D. B., M. D. Kozar, J. S. White, and K. S. Paybins (2012), Groundwater Quality in West Virginia, 1993-2008, United States Geological Survey. Report.

(13) Chapman, E. C., R. C. Capo, B. W. Stewart, C. S. Kirby, R. W. Hammack, K. T. Schroeder, and H. M. Edenborn (2012), Geochemical and strontium isotope characterization of produced waters from Marcellus Shale natural gas extraction, Environmental Science \& Technology, 46(6), 3545-3553.

(14) Clark, I. D., and P. Fritz (1997), Environmental Isotopes in Hydrogeology, CRC.

(15) Davies, R. J. (2011), Methane contamination of drinking water caused by hydraulic fracturing remains unproven, Proceedings of the National Academy of Sciences, 108(43), E871-E871.

(16) Davies, R. J., S. Mathias, J. Moss, S. Hustoft, and L. Newport (2012), Hydraulic fractures: How far can they Go?, Marine and Petroleum Geology.

(17) DePhilip, M., and T. Moberg (2010), Ecosystem Flow Recommendations for the Susquehanna River Basin, The Nature Conservancy, Report to the Susquehanna River Basin Commission and US Army Corps of Engineers, Harrisburg, PA. 
(18) DiGiulio, D., R. Wilkin, C. Miller, and G. Oberley (2011), Investigation of groundwater contamination near Pavillion, Wyoming. U.S. Environmental Protection agency draft report. Report.

(19) DOE, and NETL (2009), Modern Shale Gas Development in the United States: A Primer, pp. 1-116.

(20) Donato, S. A., R. J. Sterrett, and B. Hanna (2009), Review of the Thyne Report's Analysis and Conclusions of Mamm Creek Phase II Hydrogeologic Study.

(21) Drohan, P., M. Brittingham, J. Bishop, and K. Yoder (2012), Early Trends in Landcover Change and Forest Fragmentation Due to Shale-Gas Development in Pennsylvania: A Potential Outcome for the Northcentral Appalachians, Environmental Management, $1-15$.

(22) Dusseault, M., M. Gray, and P. Nawrocki (2000), Why oilwells leak: cement behavior and long-term consequences, paper presented at International Oil and Gas Conference and Exhibition, China.

(23) Eisenhauer, P., N. Zegre, P. Edwards, and S. Sharma (2012), Baseline Characterization of Groundwater Chemistry in an Area of Future Marcellus Shale Gas Development, paper presented at American Geophysical Union, San Francisco, CA.

(24) Encana (2013), Wellbore Construction. (http://www.encana.com/environment/water/ protection/construction.html)

(25) Engelder, T. (2009), Marcellus 2008: Report card on the breakout year for gas production in the Appalachian Basin, Fort Worth Basin Oil and Gas Magazine, 8, 11-19. 
(26) Entrekin, S., M. Evans-White, B. Johnson, and E. Hagenbuch (2011), Rapid expansion of natural gas development poses a threat to surface waters, Frontiers in Ecology and the Environment, 9(9), 503-511.

(27) US EIA (2012), Annual Energy Outlook 2012 with Projections to 2035, U.S. Department of Energy, Washington, DC.

(28) US EIA (2011), Review of Emerging Resources: U.S. Shale Gas and Shale Oil Plays, U.S. Department of Energy, Washington, DC.

(29) USEPA (2009), National Primary Drinking Water Regulations, Washington, DC.

(30) USEPA (2010). Emergency Administrative Order: Range Resources Corporation and Range Production Company. R. VI. Docket Number: SDWA-06-2011-1208.

(31) USEPA (2012), Study of the Potential Impacts of Hydraulic Fracturing on Drinking Water Resources Progress Report, Washington, DC.

(32) Penn State Extension (2009), Water Withdrawals for Development of Marcellus Shale Gas in Pennsylvania, The Pennsylvania State University.

(33) Faucette, L., C. Jordan, L. Risse, M. Cabrera, D. Coleman, and L. West (2005), Evaluation of stormwater from compost and conventional erosion control practices in construction activities, Journal of Soil and Water Conservation, 60(6), 288-297.

(34) Fisher, M., and N. Warpinski (2012), Hydraulic-Fracture-Height Growth: Real Data, SPE Production \& Operations, 27(1), 8-19.

(35) Fleeger, G. M. (1999), The Geology of Pennsylvania's Groundwater, Pennsylvania Geological Survey. (http://www.dcnr.state.pa.us/cs/groups/public/documents/document/ dcnr_014598.pdf) 
(36) Gass, T. E., J. H. Lehr, and H. W. Heiss (1977), Impact of abandoned wells on ground water, Environmental Protection Agency, Office of Research and Development, Robert S. Kerr Environmental Research Laboratory.

(37) GWPC (2009), State oil and natural gas regulations designed to protect water resources, Prepared for the US Department of Energy, National Energy Technology Laboratory, 20.

(38) Harrison, S. S. (1985), Contamination of aquifers by overpressuring the annulus of oil and gas wells, Groundwater, 23(3), 317-324.

(39) Holberger, R., and J. Truett (1976), Sediment yield from construction sites, paper presented at Proceedings of the Third Federal Inter-Agency Sedimentation Conference 1976.

(40) Kargbo, D. M., R. G. Wilhelm, and D. J. Campbell (2010), Natural gas plays in the Marcellus shale: Challenges and potential opportunities, Environmental Science \& Technology, 44(15), 5679-5684.

(41) Keech, D. K., and M. S. Gaber (1982), Methane in water wells, Water Well Journal, 36(2), 33-36.

(42) Lacombe, S., E. Sudicky, S. Frape, and A. Unger (1995), Influence of leaky boreholes on cross-formational groundwater flow and contaminant transport, Water Resources Research, 31(8), 1871-1882.

(43) Lutz, B. D., A. N. Lewis, and M. W. Doyle (2013), Generation, transport, and disposal of wastewater associated with Marcellus Shale gas development, Water Resources Research (2013).

(44) MacDonald, R. (1965), Geologic Map and Cross Section of Summit Lake West Virginia, USDA Forest Service. 
(45) Mathes, M. V., and J. S. White (2006), Methane in West Virginia Ground Water, US Geological Survey, Charleston, West Virginia.

(46) McClintock, K., and J. M. Harbor (1995), Modeling potential impacts of land development on sediment yields, Physical Geography, 16(5), 359-370.

(47) McPhillips, L., A. Creamer, T. Walter, and B. G. Rahm (2012), Baseline evaluation of groundwater quality in Central New York in the face of shale gas development, American Geophysical Union, San Francisco, CA.

(48) Mohamoud, Y. (2004), Comparison of hydrologic responses at different watershed scales, Office of Research and Development, United States Environmental Protection Agency.

(49) Molofsky, L. J., J. A. Connor, S. K. Farhat, A. S. WYLIE, and T. Wagner (2011), Methane in Pennsylvania water wells unrelated to Marcellus shale fracturing, Oil \& Gas Journal, 109(19).

(50) Mook, W. G., and d. J. J. Vries (2001), Environmental Isotopes in the Hydrological Cycle: Principles and Application, III(39), 1-121.

(51) Mulder, M. L. (2012), Ambient Geochemical and Isotopic Variations in Groundwaters Across and Area of Accelerating Shale Gas Development 100 pp, West Virginia University, Morgantown, WV.

(52) Mulder, M. L., S. Sharma, H. E. Bevans, D. B. Chambers, and J. S. White (2012), Baseline Monitoring of Groundwaters in an Area of Accelerating Shale Gas Development in North Central West Virginia, GSA Southeastern Regional Meeting 1-2 April, Ashville, NC. 
(53) Muehlenbachs, L., E. Spiller, and C. Timmins (2012), Shale Gas Development and Property Values: Differences across Drinking Water Sources, National Bureau of Economic Research. Report.

(54) Myers, T. (2012), Potential contaminant pathways from hydraulically fractured shale to aquifers, Groundwater, 50(6),872-882.

(55) Nadeau, T. L., and M. C. Rains (2007), Hydrological connectivity between headwater streams and downstream waters: how science can inform policy, JAWRA Journal of the American Water Resources Association, 43(1), 118-133.

(56) NYDEC (2011), Revised Draft SGEIS on the Oil, Gas and Solution Mining Regulatory Program. Report.

(57) OHDNR (2008), Report on the Investigation of the Natural Gas Invasion of Aquifers In Bainbridge Township of Geauga County, Ohio. Report.

(58) Olmstead, S. M., L. A. Muehlenbachs, J.-S. Shih, Z. Chu, and A. J. Krupnick (2013), Shale gas development impacts on surface water quality in Pennsylvania, Proceedings of the National Academy of Sciences.

(59) Osborn, S. G., and J. C. McIntosh (2010), Chemical and isotopic tracers of the contribution of microbial gas in Devonian organic-rich shales and reservoir sandstones, northern Appalachian Basin, Applied Geochemistry, 25(3), 456-471.

(60) Osborn, S. G., A. Vengosh, N. R. Warner, and R. B. Jackson (2011), Methane contamination of drinking water accompanying gas-well drilling and hydraulic fracturing, Proceedings of the National Academy of Sciences, 108(20), 8172-8176.

(61) Palacios, V. E. (2012), Baseline groundwater quality testing needs in the Eagle Ford Shale region, 88 pp, Duke University. 
(62) PRI (2012), Understanding Drilling Technology, Paleontological Research Institution, Ithaca, NY.

(63) Puls, R. W., and M. J. Barcelona (1996), Low-flow (minimal drawdown) ground-water sampling procedures, US Environmental Protection Agency, Office of Research and Development, Office of Solid Waste and Emergency Response.

(64) Rahm, B. G., and S. J. Riha (2012), Toward strategic management of shale gas development: Regional, collective impacts on water resources, Environmental Science \& Policy, 17,12-23.

(65) Révész, K. M., K. J. Breen, A. J. Baldassare, and R. C. Burruss (2010), Carbon and hydrogen isotopic evidence for the origin of combustible gases in water-supply wells in north-central Pennsylvania, Applied Geochemistry, 25(12), 1845-1859.

(66) Rostron, B., and C. Holmden (2000), Fingerprinting formation-waters using stable isotopes, Midale area, Williston Basin, Canada, Journal of Geochemical Exploration, 69, 219-223.

(67) Rowan, E., M. Engle, C. Kirby, and T. Kraemer (2011), Radium Content of Oil-and GasField Produced Waters in the Northern Appalachian Basin (USA) Summary and Discussion of Data, US Geological Survey Scientific Investigations Report.

(68) Roy, S. B., P. F. Ricci, K. V. Summers, C.F. Chung, and R. A. Goldstein (2005), Evaluation of the Sustainability of Water Withdrawals in the United States, 1995 to 2025, JAWRA Journal of the American Water Resources Association, 41(5), 1091-1108.

(69) Sarni, W., and J. Stanislaw (2012), No water, no energy. No energy, no water, Deloitte Center for Energy Solutions. Report.

(70) Sharma, S., and C. Frost (2009), Tracing Coalbed Natural Gas-Coproduced Water Using Stable Isotopes of Carbon, Groundwater, 46(2), 329-334. 
(71) Sharma, S., and J. K. Baggett (2011), Application of carbon isotopes to detect seepage out of coalbed natural gas produced water impoundments, Applied Geochemistry, 26(8), 1423-1432.

(72) Soeder, D. J., and W. M. Kappel (2009), Water resources and natural gas production from the Marcellus Shale, US Department of the Interior, US Geological Survey.

(73) Soil, G., and W. C. Commission (2002), Erosion and sediment control course manual, Georgia Soil and Water Conservation Commission.

(74) SRBC (2002), Guidelines for Using and Determining Passby Fows and Conservation Releases for Surface-Water and Ground-Water Withdrawal, Susquehanna River Basin Commission.( http://www.srbc.net/sitemap/using\&determiningpassbyflows.htm)

(75) Stahl, W., E. Faber, B. Carey, and D. Kirksey (1981), Near-surface evidence of migration of natural gas from deep reservoirs and source rocks, AAPG Bulletin, 65(9), 1543-1550.

(76) Szabo, Z., and V. T. DePaul (1998), Radium-226 and radium-228 in shallow ground water, southern New Jersey, US Department of the Interior, US Geological Survey.

(77) Thyne, G. (2008), Review of Phase II Hydrogeologic Study SBS LLC.

(78) Timothy Considine, R. W., Nicholas Considine, John Martin (2012), Environmental Impacts During Marcellus Shale Gas Drilling: Causes, Impacts, and Remedies, 52.

(79) USGS (2012), Alkalinity Calculator. (http://or.water.usgs.gov/alk/)

(80) USGS (2013), Trace Elements National Synthesis Project.

(http://water.usgs.gov/nawqa/trace/)

(81) Vaughn, A., and D. Pursell (2010), Frac attack: Risks, hype, and financial reality of hydraulic fracturing in the shale plays, Houston, TX: Reservoir Research Partners. 
(82) Warner, N. R., R. B. Jackson, T. H. Darrah, S. G. Osborn, A. Down, K. Zhao, A. White, and A.Vengosh (2012), Geochemical evidence for possible natural migration of Marcellus Formation brine to shallow aquifers in Pennsylvania, Proceedings of the National Academy of Sciences, 109(30), 11961-11966.

(83) Weltman-Fahs, M., and J. M. Taylor (2013), Hydraulic Fracturing and Brook Trout Habitat in the Marcellus Shale Region: Potential Impacts and Research Needs, Fisheries, 38(1), 4-15.

(84) Whiticar, M. J. (1999), Carbon and hydrogen isotope systematics of bacterial formation and oxidation of methane, Chemical Geology, 161(1), 291-314.

(85) Williams, H. F. L., D. Havens, K. Banks, and D. Wachal (2008), Field-based monitoring of sediment runoff from natural gas well sites in Denton County, Texas, USA, Environmental Geology, 55(7), 1463-1471.

(86) Wolman, M. G., and A. P. Schick (1967), Effects of construction on fluvial sediment, urban and suburban areas of Maryland, Water Resources Research, 3(2), 451-464.

(87) WRI (2012), A Perspective on the USEPA Study of Pavillion, Wyoming - Relevance and Lessons for NY. Report. 